\title{
A Neoclerodane Orthoester and Other New Neoclerodane Diterpenoids From Teucrium Yemense, Which Stimulate the Secretion of Insulin From Pancreatic Islets
}

Mohammad Nur-eAlam ( $\square$ mohnalam@ksu.edu.sa )

King Saud University

Ifat Parveen

Aberystwyth University

Barrie Wilkinson

John Innes Centre

Sarfaraz Ahmed

King Saud University

Rahman Hafizur

University of Karachi

Ahmed Bari

King Saud University

Timothy Woodman

University of Bath

Michael Threadgill

Aberystwyth University

Adnan Al-Rehaily

King Saud University

\section{Research Article}

Keywords: plant, chromatography, neoclerodane

Posted Date: December 28th, 2020

DOI: https://doi.org/10.21203/rs.3.rs-128115/v1

License: (c) (1) This work is licensed under a Creative Commons Attribution 4.0 International License.

Read Full License 
Version of Record: A version of this preprint was published at Scientific Reports on April 13th, 2021. See the published version at https://doi.org/10.1038/s41598-021-87513-3. 


\section{Abstract}

Teucrium yemense, a medicinal plant commonly grown in Saudi Arabia and Yemen, is traditionally used to treat infections, kidney diseases, rheumatism, and diabetes. Extraction of the dried aerial parts of the plant with methanol, followed by further extraction with butanol and chromatography, gave twenty novel neoclerodanes. Their structures, relative configurations and some conformations were determined by MS and 1-D and 2-D NMR techniques. Most were fairly conventional but one contained an unusual stable orthoester, one had its (C-16)-(C-13)-(C-14)-(C-15) (tetrahydro)furan unit present as a succinic anhydride and one had a rearranged carbon skeleton resulting from ring-contraction to give a central octahydroindene bicyclic core, rather than the usual decalin. Mechanisms are proposed for the biosynthetic formation of the orthoester and for the ring-contraction. Four novel neoclerodanes increased the glucose-triggered release of insulin from isolated murine pancreatic islets by more than the standard drug tolbutamide, showing that they are potential leads for the development of new anti-diabetic drugs.

\section{Introduction}

Teucrium is a genus of the Lamiaceae family. Plants in this large genus are perennial herbs, shrubs and subshrubs but present many different appearances. ${ }^{1}$ They are widespread in the Middle East, Southeast Asia, Central and South America and countries surrounding the Mediterranean Sea. ${ }^{2}$ Saudi Arabia hosts six species of Teucrium and is thought to be one of the original centres in which these plants developed. ${ }^{3}$ Various Teucrium species have been used traditionally for millennia as diuretic, diaphoretic, antiseptic and antipyretic agents. ${ }^{4}$ In Saudi Arabia, they have been used in folk medicine to treat diabetes but several other therapeutic activities have been reported in different countries. ${ }^{4-7}$ Plants of this genus have been shown to contain diterpenoids, flavonoids, iridoids, tannins, saponins, alkaloids, sterols, coumarins and glycosides. ${ }^{4,8-10}$ One species, T. yemense (Defl.), is a medicinal plant commonly grown in Saudi Arabia. It is used traditionally to treat infections, kidney diseases, rheumatism and diabetes. $8,11,12$ Moreover, extracts of a related species, T. polium, have recently been shown to have activity in animal models of diabetes. ${ }^{13,14}$

We reported previously the isolation and characterisation of six neoclerodanes from an ethyl acetate (EtOAc) extract of $T$. yemense, of which two stimulated the growth of $E$. coli but none had antimicrobial or anthelmintic activity. ${ }^{15}$ Nine other neoclerodanes had been identified from this plant by Sattar et al. without evaluation of their biological activity, ${ }^{9}$ whereas other neoclerodanes have been isolated from other Teucrium species. ${ }^{16,17}$ Neoclerodanes have been also characterised from Scutellaria species ${ }^{18,19}$ and Linaria species, ${ }^{20}$ while neoclerodanes from Salvia have been identified as inhibitors of HSP90 and as K-opioid receptor agonists. ${ }^{21-24} \mathrm{Here}$, we disclose the isolation and structures of twenty new neoclerodanes from the butanol $(\mathrm{BuOH})$ extract of $T$. yemense and report that nine examples enhance the insulin-triggered release of insulin from isolated murine pancreatic islets, indicating potential anti-diabetic activity. 


\section{Results \& Discussion}

The dried aerial parts of the plant were defatted and extracted with methanol $(\mathrm{MeOH})$. This solvent was evaporated and the residue was extracted with EtOAc, then extracted with $\mathrm{BuOH}$. The $\mathrm{BuOH}$ extract was separated by column chromatography on silica gel. Radial chromatography and HPLC yielded twenty pure compounds (Fig. 1). Their structures were elucidated using 1D and 2D nuclear magnetic resonance (NMR) and high-resolution electrospray ionisation mass spectrometry (HRESIMS) data. Their absolute configurations cannot be confirmed from these data but are assumed on the basis of precedent for related compounds. ${ }^{9,25,26}$

Compound 1. HRESIMS showed pseudomolecular ions at $m / z 457[\mathrm{M}+\mathrm{K}]^{+}, m / z 441.1509[\mathrm{M}+\mathrm{Na}]^{+}$(calc 441.1525) and $m / z 419.1690[\mathrm{M}+\mathrm{H}]^{+}$(calc 419.1706), for the formula $\mathrm{C}_{22} \mathrm{H}_{26} \mathrm{O}_{8}$. An ion was also observed at $m / z 401\left[\mathrm{M}+\mathrm{H}-\mathrm{H}_{2} \mathrm{O}\right]^{+}$, indicating a hydroxy group. Negative pseudomolecular ions were detected at $m / z 463.1605$ [M $^{2}$ formate] $]^{-}$(calc 463.1605) and $m / z 453.1316\left[\mathrm{M}+{ }^{35} \mathrm{Cl}\right]^{-}$(calc 453.1316). The ${ }^{13} \mathrm{C}$ NMR spectrum (Table S1, Supplementary Information (SI)) showed 22 discrete resonances: 2 . $\mathrm{CH}_{3}, 6 \cdot \mathrm{CH}_{2}, 7 \cdot \mathrm{CH}, 7 \cdot \mathrm{C}_{\mathrm{q}}$. The core structure was shown to be a decalin and related to the neoclerodane diterpenoids. ${ }^{9,15,16,25}$ The infra-red (IR) spectrum showed an $\mathrm{OH}\left(3536 \mathrm{~cm}^{-1}\right)$ and one y-lactone carbonyl peak $\left(1761 \mathrm{~cm}^{-1}\right)$.

In the upper part of the structure of 1 (Figure 1), the aromatic furan was characterised by ${ }^{1} \mathrm{H}$ NMR signals at $\delta 6.47(\mathrm{H}-14), \delta 7.54(\mathrm{H}-15)$ and $\delta 7.61(\mathrm{H}-16)$ (Table S1, SI). A ${ }^{1} \mathrm{H}^{-1} \mathrm{H}$ correlation spectrum (COSY) cross-peak linked $\delta 6.47(\mathrm{H}-14)$ and $\delta 7.54(\mathrm{H}-15)$. Heteronuclear single quantum (HSQC) correlation linked the ${ }^{1} \mathrm{H}$ signals to ${ }^{13} \mathrm{C}$ signals at $\delta 109.1$ (C-14), $\delta 145.6$ (C-15) and $\delta 141.80$ (C-16); the signal for C13 ( $\delta$ 126.3) was identified by a strong 3-bond heteronuclear multi-bond (HMBC) correlation to $\mathrm{H}-15$ and weaker 2-bond correlations to $\mathrm{H}-14$ and $\mathrm{H}-16$. These signals match well with those observed previously for the furans in fatimanol $\mathrm{B}$, fatimanol $\mathrm{D}$ and fatimanol $\mathrm{E} .{ }^{15}$ The spiro-lactone was identified through the chemical shift of H12 ( $\delta 5.46)$ (cf. corresponding signals in fatimanol B ( $\delta 5.51)$ and fatimanol D $(\delta$ $5.46)^{1}$. HMBC tied this proton signal to each of the furan ${ }^{13} \mathrm{C}$ signals. COSY correlation linked this $\mathrm{H}-12$ signal to the doublet signal at $\delta 2.49(2 \mathrm{H})$ and a 2-bond $\mathrm{HMBC}$ correlation confirmed that $\mathrm{C}-11$ resonated at $\delta 41$. Although the two $\mathrm{H}-11$ protons are formally diastereotopic, they are coincident for fatimanol $\mathrm{D}^{15}$ and for 1 ( $\delta 2.49$ ). Curiously, no 3-bond HMBC cross-peaks were seen linking $\mathrm{H}-12$ to the lactone carbonyl $(20-C, \delta 179.27)$ or the spiro-carbon (9-C, $\delta 49.06)$, although examination of the MM2-minimised conformation indicated that the corresponding dihedral angles $(\mathrm{H}-12)-(\mathrm{C}-12)-(\mathrm{O})-(\mathrm{C}-9)$ and $(\mathrm{H}-12)-(\mathrm{C}-12)-$ (C-11)-(C-9) are very close to $90^{\circ}$, the coupling constant minimum in the Karplus relationship. This model also suggested a rigid trans-decalin conformation for the lower part of 1. This conformational and configurational assignment was supported by $\mathrm{H}-10$ resonating as a broad doublet at $\delta 1.89$ with ${ }^{3} \mathrm{~J}=$ 11.2 $\mathrm{Hz}$ corresponding to a trans-diaxial coupling with $\mathrm{H}-1_{\mathrm{ax}}$. A nuclear Overhauser effect correlation spectroscopy (NOESY) experiment $\left(\left(\mathrm{CD}_{3}\right)_{2} \mathrm{SO}\right.$ solvent) showed a cross-peak between $\mathrm{H}-18_{\text {endo }}(\delta 3.69$ ( $\delta$ 3.87 in $\left.\mathrm{CD}_{3} \mathrm{OD}\right)$ ) and $\mathrm{H}-11$ ( $\left.\delta 2.49\right)$; this demonstrated that $\mathrm{C}-18\left(\delta 58.3\right.$ in $\left.\mathrm{CD}_{3} \mathrm{OD}\right)$ is axial. $\mathrm{H}-3$ was 
identified by its chemical shift ( $\delta 4.25)$ and by HMBC correlations to C-1 $(\delta 29)$ and C-4 ( $\delta$ 87.1). The corresponding C-3 ( $\delta 71.4)$ correlated by HSQC to H-3 and by HMBC to both $1-\mathrm{H}(\delta 1.29$ and $\delta 1.60)$ and to both $2-\mathrm{H}(\delta 1.60$ and $\delta 2.20)$. $\mathrm{H}-3$ had a trans-diaxial coupling with $\mathrm{H}-2{ }_{\mathrm{ax}}\left({ }^{3} \mathrm{~J}=10.9 \mathrm{~Hz}\right)$ and was thus axial, making 3-OH equatorial and confirming the conformation of ring $\mathrm{A}$ as chair. A strong NOESY correlation between $3-\mathrm{H}$ and $\mathrm{H}-19_{\text {exo }}(\delta 3.91)$ showed that $\mathrm{CH}_{2}-19$ was close in space to $\mathrm{H}-3$ and also axial. With $\mathrm{H}-10$ and $\mathrm{CH}_{2}-19$ both axial, the decalin must be trans-fused. $\mathrm{CH}_{3}-17$ resonated as expected as a doublet at $\delta 1.08\left({ }^{1} \mathrm{H}\right)$ and $\delta 16.1\left({ }^{13} \mathrm{C}\right)$, linked by a HSQC cross-peak. Strong 3-bond HMBC cross-peaks from $\mathrm{H}_{3}-17$ to $\mathrm{C}-9$ ( $\left.\delta 49.1\right)$ and to $\mathrm{C}-7$ ( $\left.\delta 35.2\right)$ and from $\mathrm{C} 17$ to $\mathrm{H}-7 \mathrm{ax}$ ( $\left.\delta 2.27\right)$ confirmed the location of this methyl group. The ${ }^{1} \mathrm{H}$ signal for $\mathrm{H}-7$ ax was a dd $\left({ }^{2} J_{(\mathrm{H} 7 \mathrm{ax})-(\mathrm{H}-7 \mathrm{eq})}=14.1 \mathrm{~Hz},{ }^{2} J_{(\mathrm{H}-7 \mathrm{ax})-(\mathrm{H}-8)}=12.9 \mathrm{~Hz}\right)$, showing that $\mathrm{H}-8$ is axial and, therefore, $\mathrm{CH}_{3} 17$ is equatorial. The NOESY experiment $\left(\left(\mathrm{CD}_{3}\right)_{2} \mathrm{SO}\right)$ showed a cross-peak between $\mathrm{H}_{3}-20$ and the $\mathrm{H}-11$ resonance at $\delta 2.36$ ( $\delta 2.49$ in $\mathrm{CD}_{3} \mathrm{OD}$ ), which is only possible if $\mathrm{CH}_{3}-17$ is equatorial.

The orthoacetate unit of 1 was more challenging to identify. The methyl protons gave a singlet at $\delta 1.43$, which is inappropriate for an acetate ester, with the ${ }^{13} \mathrm{CH}_{3}$ signal at $\delta$ 23.9. 2-Bond $\mathrm{HMBC}$ linked this $\mathrm{CH}_{3}$ to the orthoester carbon signal at $\delta 107.7$ / 107.8, which is inappropriate for an ester carbonyl. Thus this 2-carbon unit was not a conventional acetate ester, which was consistent with no loss of $60 \mathrm{Da}(\mathrm{HOAc})$ in the MS fragmentation. The ${ }^{1} \mathrm{H}$ NMR spectrum in $\left(\mathrm{CD}_{3}\right)_{2} \mathrm{SO}$ showed only one $\mathrm{OH}$ resonance $(\mathrm{HO}-3, \delta 5.23$, with COSY and NOESY correlations with $\mathrm{H}-3$ ); thus the oxygens in the lower part of the structure must be ethers. $\mathrm{H}-18_{\text {endo }}(\delta 3.87)$ and $\mathrm{H}-18_{\text {exo }}$ both formed $\mathrm{HMBC}$ cross-peaks with the ${ }^{13} \mathrm{C}$ signal(s) at $\delta 107.7 /$ 107.8. Thus one of these signals must have been due to the orthoester carbon (four bonds from $\mathrm{H}_{2}-18$ ) and the other due to acetal carbon $\mathrm{C}-5$ (three bonds from $\mathrm{H}_{2}-18$ ). This confirmed the ring-closure of the (C-

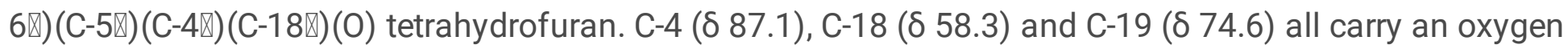
as shown by their ${ }^{13} \mathrm{C}$ chemical shifts. These data are consistent with the orthoacetate structure shown in Fig. 1 for 1 (fatimanol F, a novel compound). Analogue 21, which contains the acetal and orthoacetate structures but only differs from 1 in that it lacks HO-3, was reported ${ }^{27}$ as a product of the hightemperature pyrolysis of 19-acetylgnaphalin.

Compound 2. HRESIMS showed a pseudomolecular ion at $m / z 421.1855[\mathrm{M}+\mathrm{H}]^{+}$(calc 421.1862) for the formula $\mathrm{C}_{22} \mathrm{H}_{28} \mathrm{O}_{8}$. Fragment ions were seen at $m / z 379[\mathrm{M}+\mathrm{H} \text { - ketene }]^{+}$and $m / z 361[\mathrm{M}+\mathrm{H}-\mathrm{AcOH}]^{+}$, showing an acetate ester. Twenty-two discrete ${ }^{13} \mathrm{C}$ NMR signals were observed $\left(2 \cdot \mathrm{CH}_{3}, 6 \cdot \mathrm{CH}_{2}, 8 \cdot \mathrm{CH}, 6\right.$. $\mathrm{C}_{\mathrm{q}}$ (ester and ketone). IR confirmed these carbonyls, with bands at $1712 \mathrm{~cm}^{-1}$ and $1796 \mathrm{~cm}^{-1}$, respectively. A hydroxy group absorbed at $3478 \mathrm{~cm}^{-1}$.

The NMR data (Table S1, SI) showed that 2 had a neoclerodane structure. The aromatic furan was shown by ${ }^{1} \mathrm{H}$ NMR signals at $\delta 6.41(\mathrm{H}-14), \delta 7.43(\mathrm{H}-15)$ and $\delta 7.42(\mathrm{H}-16)$, with HSQC correlations to $\mathrm{C}-14(\delta$ $108.8), C-15$ ( $\delta 143.8)$ and $C-16$ ( $\delta 139.6)$, respectively. The $C-13$ signal $(\delta 124.8)$ was identified by HMBC correlations with $\mathrm{H}-14, \mathrm{H}-15$, and $\mathrm{H} 16$. C-13, C-14, and $\mathrm{C}-16$ showed HMBC cross-peaks with a double 
doublet (dd) aliphatic proton signal at $\delta 5.25$, which was assigned as $\mathrm{H}-12$. HSQC correlated this signal with $\mathrm{C}-12$ ( $\delta 71.2)$. The corresponding signal for $\mathrm{H}-12$ in the lactone 1 is downfield at $\delta 5.46$, whereas $\mathrm{H}-$ 12 in the alcohol 3 resonates upfield at $\delta 4.85$. These comparisons suggest that the electron-density at $\mathrm{H}$ 12 in $\mathbf{2}$ is intermediate between that in the lactone $\mathbf{1}$ and the alcohol $\mathbf{3}$ and is consistent with the hemiacetal / lactol structure in 2. A strong 3-bond HMBC cross-peak linked C-12 with the hemiacetal H-20 singlet at $\delta$ 5.54. HSQC identified C-20 ( $\delta$ 99.7). The five-membered lactol was completed by identification of both $\mathrm{H}-11$ signals ( $\delta 1.93 \mathrm{dd}, \delta 2.34 \mathrm{dd}$ ) by HBMC correlations with $\mathrm{C} 20$, location of $\mathrm{C}-12(\delta 44.2)$ by HSQC correlation with $\mathrm{H}-12$, and characterisation of the quaternary spiro carbon C-9 ( $\delta 53.6)$ by HMBC correlations with $\mathrm{H}-12$ and $\mathrm{H}-20$. COSY linked both $\mathrm{H}-11$ and $\mathrm{H}-12$. In the lower part, the hydroxy group was located at C-3 through the chemical shifts of $\mathrm{H}-3(\delta 4.11)$ and $\mathrm{C}-3(\delta 66.4)$. $\mathrm{H}-3$ had been identified by HMBC correlation to $\mathrm{C}-5$ ( $\delta$ 63.6) and $\mathrm{C}-3$ had been identified by HMBC correlation to $\mathrm{H}-1$ ( $\delta 2.22$ and $\delta$ $2.64)$ and $\mathrm{H}-2$ ( $\delta 1.36$ and $\delta 2.22)$. Observation of two geminally coupled doublets $(\mathrm{H}-18)$ at $\delta 2.81$ and $\delta$ $3.14\left({ }^{2} \mathrm{~J}=5.3 \mathrm{~Hz}\right)$ revealed the spiro-oxirane. This was shown to be at C-4 by HMBC from these $\mathrm{H}-18$ protons to $\mathrm{C}-5(\delta 63.6)$ and from $\mathrm{H}-3$ to $\mathrm{C}-18(\delta$ 43.7). $\mathrm{C}-6$ was a ketone, as shown by its chemical shift $(\delta$ 206.2) and by HMBC cross-peaks to both $\mathrm{H}-7$ signals ( $\delta 2.28$ and $\delta 2.72$ ) and a 4-bond HMBC correlation with $\mathrm{CH}_{3}$-17. Examination of a model of 2 suggested that ring $\mathrm{B}$ was in a flattened-chair conformation,

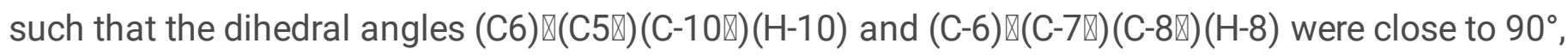
explaining the lack of these 3-bond $\mathrm{HMBC}$ interactions. The acetoxymethyl $\left(\mathrm{AcOCH}_{2}-\right)$ group was defined by $\mathrm{CH}_{3} 2^{\prime}\left(\delta_{\mathrm{H}} 2.07, \delta_{\mathrm{C}} 21.1\right)$ and the ester carbonyl $\mathrm{C}-1$ ' $\left(\delta\right.$ 171.2). HMBC cross-peaks between $\mathrm{C}^{\prime}$ ' and the geminally coupled doublets for $\mathrm{H}_{2}-19$ ( $\delta 4.72$ and $\delta 4.83$ ) confirmed the $\mathrm{AcOCH}_{2} ; \mathrm{HMBC}$ cross-peaks from these two protons to the ketone (C-6), to quaternary $\mathrm{C}-5$ and to the spiro-oxirane carbon (C-4) demostrated that this unit was located at $\mathrm{C}-5$. Rings $\mathrm{A}$ and $\mathrm{B}$ were shown to be in chair conformations by examining relevant ${ }^{3} \mathrm{~J}$ coupling constants. For example, the $\mathrm{H}-7$ ax signal ( $\left.\delta 2.72\right)$ was a broad triplet with $3 J=2 J=14.6 \mathrm{~Hz}$, indicating diaxial and geminal couplings, respectively. $\mathrm{H}-7_{\text {eq }}(\delta 2.28)$ only showed axialequatorial and geminal couplings. Thus Me-17 is equatorial and $\mathrm{H}-8$ is axial and the chair conformation

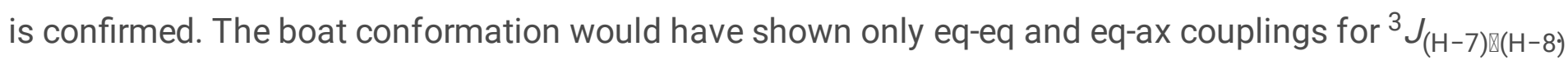

The NMR spectra showed, in addition to the peaks for this major compound, a full set of peaks for a minor component, with similar chemical shifts and multiplicities. This minor set of peaks integrated for ca. $10 \%$ of the major compound present. As the sample gave only one pure peak on HPLC, we ascribed these peaks to a minor diastereoisomer in slow equilibrium with the major diastereoisomer. These are likely to be epimers at the lactol hemiacetal C-20. This assignment was supported by the largest differences in chemical shift between the epimers being for $\mathrm{H}-3(\Delta \delta 0.1 \mathrm{ppm}), \mathrm{H}-14(\Delta \delta 0.05 \mathrm{ppm})$, and $\mathrm{H}_{2}-19(\Delta \delta 0.2)$, as these four protons are close in space to the epimeric $\mathrm{C}-20$. We assign the structure 2 (Fig. 1) to this novel compound, fatimanone B.

Compound 3. Negative-ion HRESIMS showed ions at $m / z$ 407.1690 $[\mathrm{M}-\mathrm{H}]^{-}$(calc 407.1706) for the formula $\mathrm{C}_{21} \mathrm{H}_{28} \mathrm{O}_{8}$. Positive-ion HRESIMS revealed a pseudomolecular ion at $\mathrm{m} / z 409[\mathrm{M}+\mathrm{H}]^{+}$and a fragment ion at $m / z 379.1747\left[\mathrm{M}+\mathrm{H}-\mathrm{H}_{2} \mathrm{C}=\mathrm{O}\right]^{+}$(calc 379.1757). Twenty-one discrete ${ }^{13} \mathrm{C}$ NMR signals 
were observed: $2 \cdot \mathrm{CH}_{3}, 6 \cdot \mathrm{CH}_{2}, 7 \cdot \mathrm{CH}, 6 \cdot \mathrm{C}_{\mathrm{q}}$, including a carbonyl $(\delta 172.5)$. IR showed bands for $\mathrm{OH}$ $\left(3513 \mathrm{~cm}^{-1}\right)$ and one carbonyl $\left(1716 \mathrm{~cm}^{-1}\right)$.

The NMR data (Table S1, SI) indicated that $\mathbf{3}$ was a neoclerodane. The upper part was an aromatic furan, with ${ }^{1} \mathrm{H}$ NMR signals (Table S1, SI) at $\delta 6.42(\mathrm{H}-14), \delta 7.39(\mathrm{H}-16)$ and $\delta 7.40(\mathrm{H}-15)$. The furan ${ }^{13} \mathrm{C}$ NMR signals were at $\delta 108.4$ (C-14), $\delta 130.1$ (C-13), $\delta 138.6$ (C-16) and $\delta 143.9$ (C-15), with appropriate HSQC and HMBC connectivities. The chemical shift of $\mathrm{H}-12(\delta 4.85)$ showed that it was not part of a lactone or lactol system, confirmed by the lack of a HMBC cross-peak to the signal for carbonyl C-20 ( $\delta 172.5)$. The identity of $\mathrm{H}-12$ signal was confirmed by HMBC cross-peaks to $\mathrm{C}-13, \mathrm{C}-14$, and $\mathrm{C}-16$. Further HMBC crosspeaks were seen from $\mathrm{H}-12$ to $\mathrm{C}-11$ ( $\delta 35.8$ or $\delta 40.0)$ and to $\mathrm{C}-9$ ( $\delta 48.5)$, linking this upper side-chain to the main decalin. The configuration at $\mathrm{C}-12$ could not be established. The bridging lactone was established by HMBC cross-peaks between carbonyl C-20 and $\mathrm{H}_{2} 19$ ( $\delta 4.45$ and $\delta 4.68$ ). The identity of $\mathrm{H}_{2} 19$ had been confirmed by each signal being a doublet with only geminal coupling ${ }^{2} \mathrm{~J}=12.5 \mathrm{~Hz}$ ) and by HMBC cross-peaks to the $\mathrm{C}-6(\delta 110.0)$ and to $\mathrm{C}-4(\delta 84.1)$. $\mathrm{C}-19(\delta 66.4)$ was identified by HSQC crosspeaks to $\mathrm{H}_{2}-19$ and by strong $\mathrm{HMBC}$ to $\mathrm{H}-10(\delta 2.24-2.48 \mathrm{~m})$. The signal at $\delta 72.8$ was assigned to $\mathrm{C}-3$ on the basis of HMBC cross-peaks to both $\mathrm{H}-2$ ( $\delta 1.4$ and $\delta 2.1$ ) and to one of the $\mathrm{H}-1$ signals $(\delta 2.35)$. $\mathrm{H}-3$ ( $\delta$ 3.87) was characterised by a HSQC cross-peak to $\mathrm{C}-3$, COSY cross-peaks to both $\mathrm{H}-2$ and HMBC cross-

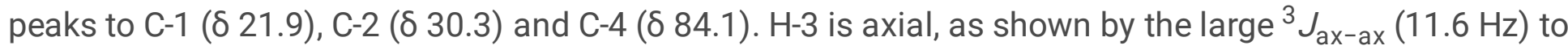
$\mathrm{H}-2_{\mathrm{ax}}$. The $\mathrm{H}-1$ signal at $\delta 1.29$ is a quartet $(J=13.2 \mathrm{~Hz})$; thus this signal is for $\mathrm{H}-1_{\mathrm{ax}}$. NOESY correlations from $\mathrm{H}-3$ to one $\mathrm{H}-19$ ( $\delta 4.45$ ) and to $\mathrm{H}-1_{\mathrm{ax}}$ showed that these are on the same face of the decalin and thus that the decalin is trans-fused and that ring $\mathrm{A}$ is in the chair conformation. The conformation of ring $B$ is less clear, owing to overlap of ${ }^{1} \mathrm{H}$ NMR signals but MM2-minimisation suggests that it may be a flattened boat. The fused tetrahydrofuran and the acetal were identified as follows. Acetal carbon $\mathrm{C}-6$ was characterised by its chemical shift $(\delta 110.0)$ and by HMBC cross-peaks to both $\mathrm{H}-19$. Further HMBC correlations were seen to the doublets at $\delta_{H} 3.90$ and $\delta_{H} 4.45$, showing that they were due to $\mathrm{H}_{2}-18$ and demonstrating the closure of the tetrahydrofuran ring. The acetal at $\mathrm{C}-6$ was identified by observation of an OMe group $\left(\delta_{H} 3.40, \delta_{C} 48.9\right)$, linked by $H M B C$ to $C-6$. These data characterise the structure of 3 , fatimanol G, as shown in Fig. 1. This structure is identical to that of teulepicephin 22, with the exception of the acetal (hemiacetal in 14$)^{15}$; the spectroscopic features are very similar, suggesting a similar conformation.

Compound 4. HRESIMS showed pseudomolecular ion peaks at $\mathrm{m} / z 383.1113[\mathrm{M}+\mathrm{Na}]^{+}$(calc 383.1107) and $m / z$ 384.1148, [M + Na] $]^{+}$(calc for ${ }^{12} \mathrm{C}_{18}{ }^{13} \mathrm{CH}_{20} \mathrm{NaO}_{7}, 384.1140$ ), appropriate to the formula $\mathrm{C}_{19} \mathrm{H}_{20} \mathrm{O}_{7}$. Low-intensity pseudomolecular ions were also observed at $m / z 361[\mathrm{M}+\mathrm{H}]^{+}$and $m / z 399[\mathrm{M}+\mathrm{K}]^{+}$. The ${ }^{13} \mathrm{C}$ NMR spectrum contained signals for 19 discrete carbons: $1 \cdot \mathrm{CH}_{3}, 4 \cdot \mathrm{CH}_{2}, 7 \cdot \mathrm{CH}, 7 \cdot \mathrm{C}_{\mathrm{q}}$ (including two carbonyls). The IR indicated hydroxy groups $\left(3614 \mathrm{~cm}^{1}\right)$ and two carbonyls $\left(1715,1701 \mathrm{~cm}^{-1}\right)$.

The ${ }^{1} \mathrm{H}$ NMR spectrum (Table S2, SI) contained two very similar sets of signals, in ca. 1:1 ratio, suggesting diastereoisomers which interconverted slowly on the ${ }^{1} \mathrm{H}$ NMR timescale. This may indicate a 
cyclic hemiacetal (cf. 2). Detailed assignment of the signals was challenging, as many overlapped between the two stereoisomers. Taken together, the NMR data showed that $\mathbf{4}$ had a neoclerodane core. As for 1-3, the upper part was an aromatic furan, with ${ }^{1} \mathrm{H}$ NMR signals at $\delta 6.49(\mathrm{H}-14), \delta 7.55(\mathrm{H}-15)$ and $\delta$ $7.61(\mathrm{H}-16)$. The signals for $\mathrm{H}-15$ and $\mathrm{H}-16$ were distinguished by a NOESY cross-peak from the former to $\mathrm{H}-14$. The ${ }^{13} \mathrm{C}$ NMR signals for this ring were at $\delta 124.7$ (C-13), $\delta 107.9$ (C-14), $\delta 139.6$ (C-15) and $\delta 144.3$ (C-16), which were identified by appropriate HSQC and HMBC. The spiro-lactone was initially identified by the chemical shift of H-12 ( $\delta 5.59)$, corresponding to a benzylic ester. This signal showed an HSQC crosspeak to C-12 ( $\delta 72.3)$ and HMBC cross-peaks to C-13, C-14, C-16, and C-11 ( $\delta$ 40.2, weak 2-bond crosspeak). HSQC then identified the dd signal at $\delta 2.73$ as being due to one $\mathrm{H}-11$ and the two signals at $\delta 2.56$ and $\delta 2.57$ (both dd, with each integrating for $0.5 \mathrm{H}$ ) as due to the other $\mathrm{H} 11$. The ${ }^{13} \mathrm{C}$ signal at $\delta 176.4$ was shown to be due to the lactone carbonyl C-20 by HMBC cross-peaks to $\mathrm{H}-11$ ( $\delta 2.73), \mathrm{H}-8(\delta 2.2)$, and $\mathrm{H}-10(\delta 2.85)$. $\mathrm{H}-3(\delta 4.41)$ and $\mathrm{C}-3$ ( $\delta 60.5)$ had the expected downfield chemical shifts arising from the $\mathrm{OH}$. COSY then identified $\mathrm{H}-2$ at $\delta 1.66$ and $\delta 2.10$, with HSQC showing $\mathrm{C}-2$ ( $\delta 21.6)$. Further COSY crosspeaks then showed the resonances for $\mathrm{H}-1$ at $\delta 1.64$ and $\delta$ 2.3. The lower fused butenolide became evident through $\mathrm{HMBC}$ cross-peaks from $\mathrm{H}-10$ to the alkene $\mathrm{C}_{\mathrm{q}}$ peaks for $\mathrm{C}-4$ ( $\delta$ 128.5) and $\mathrm{C}-5$ ( $\left.\delta 163.0\right)$. These were distinguished from each other by their chemical shifts and by observation of a HMBC crosspeak from $\mathrm{C}-4$ to $\mathrm{H}-2$ ( $\delta 2.01)$. The carbonyl $\mathrm{C}-18$ signal was at $\delta 170.1$. The lactone was completed by $\mathrm{C}-$ 6 ( $\delta$ 102.4), which shows HMBC correlations with both $\mathrm{H}-7$ signals, $\mathrm{H}-8$ and $\mathrm{H}-10$. Interestingly, there is also a weak 4-bond $\mathrm{HMBC}$ cross-peak between $\mathrm{H}-17$ (the methyl group) and $\mathrm{C}-6$. The extensive overlap of many of the ${ }^{1} \mathrm{H}$ NMR signals for the two diastereoisomers precluded detailed assignments of the conformations of the decalins. We assign structure 4 (Fig. 1) to this novel compound, fatimanol $\mathrm{H}$.

Compound 5. HRESIMS showed pseudomolecular ion peaks at $m / z 425.1197[\mathrm{M}+\mathrm{Na}]^{+}$(calc 425.1212) and $m / z 403.1378[\mathrm{M}+\mathrm{H}]^{+}$(calc 403.1393), corresponding to the formula $\mathrm{C}_{21} \mathrm{H}_{22} \mathrm{O}_{8}$. The spectrum also contained a peak at $m / z$ 827.2509 [2 $\mathrm{M}+\mathrm{Na}]^{+}$(calc 827.2527). The ${ }^{13} \mathrm{C}$ NMR spectrum contained signals for twenty-one discrete carbons: $2 \cdot \mathrm{CH}_{3}, 4 \cdot \mathrm{CH}_{2}, 7 \cdot \mathrm{CH}, 8 \cdot \mathrm{C}_{\mathrm{q}}$. The IR showed absorbances for a hydroxy group $\left(3618 \mathrm{~cm}^{-1}\right)$ and three carbonyls $\left(1763,1715,1701 \mathrm{~cm}^{-1}\right)$. The NMR spectra (Table S2, SI) were very similar to those for 4 , with the exception of additional methyl signals at $\delta_{H} 2.05 / \delta_{C} 20.9$, an additional carbonyl signal at $\delta_{\mathrm{C}} 172.1$, and a marked downfield change in the chemical shifts of $\mathrm{H}-3(\delta$ $5.59, \Delta \delta 1.18 \mathrm{ppm})$ and $\mathrm{C}-3(\delta 64.65, \Delta \delta 4.16 \mathrm{ppm})$. These indicate that $\mathbf{5}$ is the 3-0-acetate ester of $\mathbf{4}$. The ${ }^{1} \mathrm{H}$ NMR spectrum contained only one set of signals, showing that one of the possible hemiacetal diastereoisomers had significantly lower energy than the other but it was not possible to determine which from the spectroscopic data. The methyl protons $\left(\mathrm{H}-2^{\prime}, \delta 2.05\right)$ of the acetate showed a strong $\mathrm{HMBC}$ to the corresponding ester carbonyl (C-1', $\delta 170)$. C-1' also showed a cross-peak to H-3, confirming the location of the ester. We assign structure 5 (Fig. 1) to this novel compound, fatimanol I.

Compound 6 was also closely related to 4. Pseudomolecular ions were seen in HRMS at $m / z 397.1248$ $[\mathrm{M}+\mathrm{Na}]^{+}$(calc 397.1263) and $\mathrm{m} / \mathrm{z} 375.1429[\mathrm{M}+\mathrm{H}]^{+}$(calc 375.1444), consistent with the formula $\mathrm{C}_{20} \mathrm{H}_{22} \mathrm{O}_{7}$. A ${ }^{13} \mathrm{C}$ isotopomer peak was observed at $\mathrm{m} / z 398.1282$ (calc 398.1297). The ${ }^{13} \mathrm{C}$ NMR 
spectrum showed discrete signals for $2 \cdot \mathrm{CH}_{3}, 4 \cdot \mathrm{CH}_{2}, 7 \cdot \mathrm{CH}$ and $7 \cdot \mathrm{C}_{\mathrm{q}}$. The ${ }^{1} \mathrm{H}$ and ${ }^{13} \mathrm{C}$ NMR spectra (Table S2, SI) (with 2D spectra) were very similar to those for 4, with the addition of signals for a methoxy group $\left(\delta_{H} 3.19, \delta_{C} 51.0\right)$. The protons of this group showed a strong $H M B C$ cross-peak to the ${ }^{13} \mathrm{C}$ signal for $\mathrm{C}-6(\delta$ 150.8), identifying the methoxy group as being part of an acetal at this position. These data demonstrate that $\mathbf{6}$ (fatimanol J, Fig. 1) has the novel structure shown.

Compound 7. HRESIMS contained a pseudomolecular ion at $m / z 425.1459$, corresponding to [M - $\mathrm{H}^{-}$ (calc 425.1526) for the formula $\mathrm{C}_{20} \mathrm{H}_{26} \mathrm{O}_{10}$. The ${ }^{13} \mathrm{C}$ NMR spectrum showed discrete resonances for twenty carbons: $1 \cdot \mathrm{CH}_{3}, 6 \cdot \mathrm{CH}_{2}, 6 \cdot \mathrm{CH}, 7 \cdot \mathrm{C}_{\mathrm{q}}$. The IR contained absorbances for two carbonyls $\left(1769 \mathrm{~cm}^{-1}, 1737 \mathrm{~cm}^{-1}\right)$ and $\mathrm{OH}\left(3433 \mathrm{~cm}^{-1}\right)$. The NMR data (Table S2, SI) suggested a neoclerodane core. The upper part contained a hydroxyfuranone ring, as in fatimanol $A^{15}$. This cyclic acetal was represented by $\mathrm{H}-14$ ( $\delta$ 7.17), which showed an HSQC cross-peak to $C 14$ ( $\delta 146.6)$; the downfield shifts of these signals were due to the enone system. From H-14, 2-bond HMBC cross-peaks were seen to $\mathrm{C}-13$ ( $\delta$

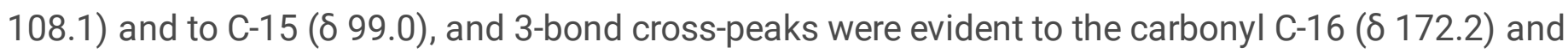
(weakly owing to the adverse dihedral angle) to $\mathrm{C}-12$ ( $\delta 64.0)$. $\mathrm{H}-14$ did not show a COSY cross-peak to the hemiacetal proton $\mathrm{H}-15$ ( $\delta 5.88$ ), again owing to the small coupling constant consequent to a dihedral angle approaching $90^{\circ}$. HSQC identified $\mathrm{H}-12$ as part of a complex multiplet at $\delta$ ca. 4.6. A 2-bond HMBC from $\mathrm{H}-12$ then led to identification of $\mathrm{C}-11$ ( $\delta 41.3$ ), from which HSQC showed the two signals for $\mathrm{H}-11$ ( $\delta$ $1.6, \delta 2.25)$. From the downfield $\mathrm{H}-11$ signal, it was then possible to use $\mathrm{HMBC}$ to identify the signals for C-9 ( $\delta 50.2), C-10(\delta 43.9)$ and the saturated lactone carbonyl C-20 ( $\delta 174.6)$. This lactone was confirmed by HMBC cross-peaks from C-20 to H-19 ( $\delta 4.58, \delta 4.64)$, and the latter were linked on to C-4 ( $\delta 85.6), \mathrm{C}-5$ $(\delta$ 49.7) and C-6 ( $\delta$ 108.2). A 2-bond HMBC correlation from C-4 identified $\mathrm{H}-3$ ( $\delta$ 3.83). The latter then gave an HMBC cross-peak to the methylene C-18 ( $\delta 75.6)$ with $\mathrm{H}-18(\delta 3.97 \mathrm{~d}(\mathrm{~J}=10.4 \mathrm{~Hz}), \delta 4.35 \mathrm{~d}(\mathrm{~J}=$ 10.4)). The downfield $\mathrm{H}-19$ also gave a 3-bond $\mathrm{HMBC}$ with $\mathrm{C}-10$, completing the lower lactone ring. $\mathrm{H}-3$ resonated as a dd $(J=11.6,5.9 \mathrm{~Hz})$, the larger of the two coupling constants indicating that this proton is axial. Completing the features of the lower part of the structure, $\mathrm{H}-18(\delta 4.35)$ showed a 3-bond HMBC with the hemiacetal carbon C-6. We assign the novel structure 7 (Fig. 1) to this compound, fatimanol K.

Compound 8. HRESIMS showed a pseudomolecular ion at $m / z 519.2212[\mathrm{M}+\mathrm{Na}]^{+}$(calc 519.2206) for the formula $\mathrm{C}_{25} \mathrm{H}_{36} \mathrm{O}_{10}$. The ${ }^{13} \mathrm{C}$ NMR spectrum showed twenty-five discrete resonances: $4 \cdot \mathrm{CH}_{3}, 8 \cdot \mathrm{CH}_{2}$, $6 \cdot \mathrm{CH}$, and $7 \cdot \mathrm{C}_{\mathrm{q}}$. Bands for $\mathrm{OH}\left(3615 \mathrm{~cm}^{1}\right)$ and three ester / lactone carbonyls $\left(1744,1734,1695 \mathrm{~cm}^{-1}\right)$ were seen in the IR spectrum. Combined interpretation of the NMR spectra (Table S3, SI) showed that 8 was a neoclerodane. The upper ring was a furan-2-one. The acetal proton $\mathrm{H}-15$ resonated as a doublet at $\delta 5.84$, with a small coupling constant $(2 \mathrm{~Hz})$ to $\mathrm{H}-14(\delta 7.02)$ confirmed by COSY. HSQC then identified C15 ( $\delta$ 104.6) and C-14 ( $\delta$ 144.8). The latter was appropriate for the $\beta$ carbon of an enone. HMBC linked $\mathrm{H}-$

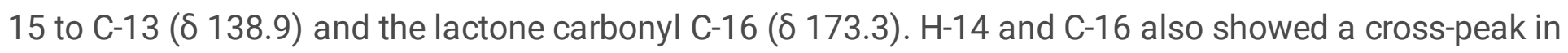
HMBC. The IR band at $1695 \mathrm{~cm}^{-1}$ was assigned to this $a, \beta$-unsaturated ester. The methoxy protons $(\delta$ 3.52) showed a HMBC cross-peak to C-15, demonstrating the location of the OMe. HSQC identified the methoxy carbon signal at $\delta$ 57.3. HMBC from C-13 to both $\mathrm{H}-12$ ( $\delta 2.15$ and $\delta 2.28$ ) and to both $\mathrm{H} 11$ ( $\delta$ 
1.4 and $\delta 2.25)$ confirmed the attachment of the methoxyfuranone ring at C-12. C-11 ( $\delta$ 34.6) and C-12 ( $\delta$ 19.3) were identified by HSQC. A further HMBC cross-peak from $\mathrm{H}-11(\delta 1.4)$ to the ${ }^{13} \mathrm{C}$ signal at $\delta 66.5$ $\left(\mathrm{CH}_{2}\right)$ showed that the latter was due to $\mathrm{C}-20$. HSQC confirmed the geminally coupled doublets $(\delta 3.97$ and $\delta 4.03)(\mathrm{J}=12.0 \mathrm{~Hz})$ as due to the two $\mathrm{H}-20$. These were linked by $\mathrm{HMBC}$ to the carbonyl ${ }^{13} \mathrm{C}$ signal at $\delta 172.6$ and thence to the acetate protons at $\delta 2.06$. Both $\mathrm{H}-20$ signals had 3-bond HMBC correlations with C-10 ( $\delta 47)$ and C-20 had HMBC correlation with the signal with H-8 $(\delta 1.7)$. H-10 ( $\delta 1.7)$ and C-8 ( $\delta$ 35.2 or 35.1) were then identified by HSQC. The $\mathrm{C}-\mathrm{Me}$ group $(\mathrm{H}-17)$ resonated as a doublet at high field $(\delta$ 0.97), with $\mathrm{C}-17$ at $\delta$ 16.5. $\mathrm{HMBC}$ cross-peaks from $\mathrm{H}_{3} \mathrm{C}-20$ linked to both $\mathrm{H}-7$ ( $\delta 1.7$ and $\delta 1.8$ ), from which C-7 ( $\delta 30.8)$ could be identified by HSQC. A weak 4-bond HMBC cross-peak was observed between $\mathrm{H}-17$ and $\mathrm{C}-6$ ( $\delta 74.3)$, as in 2 and 4. The chemical shift of this carbon and of the attendant $\mathrm{H}-6(\delta 3.78)$ suggested the presence of an oxygen substituent. $\mathrm{H}-6$ had 3-bond $\mathrm{HMBC}$ correlations with C-4 ( $\delta 66.9)$ and with C-19 ( $\delta 63.7)$. HSQC identified the geminally coupled $\mathrm{H}-19$ protons ( $\delta 4.43$ and $\delta 4.65)$. HMBC from these latter protons confirmed the lower acetate ester carbonyl $(\delta 172.7)$, linked on to the methyl proton signal at $\delta 2.06$, co-incident with the other acetate ${ }^{1} \mathrm{H}$ NMR signal. Weak 2-bond HMBC crosspeaks from $\mathrm{C}-4$ identified the oxirane protons $\mathrm{H}-18$ at $\delta 3.01$ and $\delta 3.21$, while a stronger 2-bond crosspeak showed H-3 ( $\delta 4.00)$, with its corresponding C-3 ( $\delta 66.5)$.

The relative stereochemical configurations were largely determined by use of NOESY. An MM2-minimised structure suggested that the decalin would have both rings in chair conformations. Strong NOESY crosspeaks showed that $\mathrm{H}-17$ and $\mathrm{H}-20$ were cis to each other on the lower face. Similarly, $\mathrm{H}_{2}-19$ were shown to be on the lower face by strong NOESY cross-peaks to $\mathrm{H}-20$, with these methylenes being diaxial on ring $\mathrm{B}$. Further strong NOESY cross-peaks from both $\mathrm{H}-19$ to $\mathrm{H}-3$ confirmed the latter as axial down on ring $\mathrm{A}$ and a cross-peak to $\mathrm{H}-1$ ( $\delta$ 2.1) also suggested that this was on the lower face. On the upper face, the downfield $\mathrm{H}-18$ signal ( $\delta 3.21$ ) gave a cross-peak to $\mathrm{H}-6$ ( $\delta 3.78)$, which also allowed differentiation of the two oxirane proton signals. The relative configuration at C-15 could not be determined. These data show the structure of 8 (Fig. 1), fatimanol L.

Compound 9. HRESIMS showed pseudomolecular ion peaks at $m / z 535.2189[\mathrm{M}+\mathrm{Na}]^{+}$(calc 535.2155) and $m / z 513.2350[\mathrm{M}+\mathrm{H}]^{+}$(calc 531.2336), corresponding to the formula $\mathrm{C}_{25} \mathrm{H}_{36} \mathrm{O}_{11}$. The ${ }^{13} \mathrm{C} \mathrm{NMR}$ spectrum complied, with twenty-five discrete signals: $4 \cdot \mathrm{CH}_{3}, 7 \cdot \mathrm{CH}_{2}, 7 \cdot \mathrm{CH}, 7 \cdot \mathrm{C}_{\mathrm{q}}$. The IR showed OH $\left(3546 \mathrm{~cm}^{-1}\right)$ and three carbonyls $\left(1764,1752,1708 \mathrm{~cm}^{1}\right)$. The NMR spectra (Table S3, SI) showed considerable similarity to those for $\mathbf{8}$, except in the C-11 / C-12 region and the upper methoxyfuran. The structure of the trans-decalin and the lower appendages were identical to those of $\mathbf{8}$. HMBC from C-11 ( $\delta$ 38.0) identified $\mathrm{H}-12$ ( $\delta 4.56)$; the downfield chemical shift of this peak indicated that a hydroxy group. HSQC identified C-12 ( $\delta$ 63.8). $\mathrm{H}-12$ was also linked by COSY cross-peaks to both $\mathrm{H}-11$ ( $\delta 1.75$ and $\delta$ 1.80). A strong 3-bond HMBC from $\mathrm{H}-12$ showed the signal at $\delta 144.8$ to be due to $\mathrm{C}-14$, with HSQC identifying $\mathrm{H} 14$ ( $\delta$ 7.13). Appropriate HMBC and HSQC correlations then identified C-13 ( $\delta 144.2), \mathrm{C}-15$ ( $\delta$ $104.2), \mathrm{H}-15$ ( $\delta 5.88)$ and $\mathrm{C}-16(\delta 171.7)$. The methoxy group protons resonated as two singlets $(\delta 3.54$ and $\delta 3.55)$, each integrating for $1.5 \mathrm{H}$, suggesting that 9 was a mixture of epimers at $\mathrm{C}-15$. The corresponding methoxy ${ }^{13} \mathrm{C}$ signal was linked by HMBC to H-15. NOESY also linked together the upper 
part of the structure. Strong cross-peaks were seen linking $\mathrm{H}-15$ with the methoxy group and with $\mathrm{H}-14$. Furthermore, $\mathrm{H}-14$ was linked by NOESY with $\mathrm{H}-12$. Addressing the relative configurations of 9 (except for the mixture of epimers at C-15), strong NOESY cross-peaks were seen from $\mathrm{H}-8(\delta 1.94)$ to $\mathrm{H}-6$ ( $\delta 3.78)$, to $\mathrm{H}-10$ ( $\delta 2.22)$ and to $\mathrm{H}-12$, showing that all of these are on the upper face of the bicycle. Noesy also linked $\mathrm{H}-6$ with one $\mathrm{H}-18$ ( $\delta 3.17$ ), confirming that the latter is on the upper face and differentiating the two $\mathrm{H}-18$ signals. On the lower face, one $\mathrm{H}-19$ ( $\delta 4.42)$ formed a NOESY cross-peak with $\mathrm{H}-3(\delta 4.00)$ and the other $\mathrm{H}-19$ ( $\delta 4.71)$ was close in space with $\mathrm{H}-20$ ( $\delta 3.95)$. The ${ }^{1} \mathrm{H}$ signals for $\mathrm{H}-2$ were differentiated by a NOESY cross-peak from $\mathrm{H}-10$ to $\mathrm{H}-2$ ax $(\delta 2.10)$. The relative configuration at $\mathrm{C}-12$ could not be determined. The structure of this novel compound is thus 9 (Fig. 1), fatimanol M.

Compound 10. HRESIMS showed a pseudomolecular ion at $\mathrm{m} / \mathrm{z} 425.1452\left[\mathrm{M}-\mathrm{H}^{-}{ }^{-}\right.$(calc 425.1448), corresponding to the formula $\mathrm{C}_{20} \mathrm{H}_{26} \mathrm{O}_{10}$. Smaller pseudomolecular ions were seen at $\mathrm{m} / z$ 426.1485 [M $\mathrm{H}^{-}$(calc 426.1481) and $\mathrm{m} / \mathrm{z} 427.1520[\mathrm{M}-\mathrm{H}]^{-}$(calc 427.1515) for ${ }^{13} \mathrm{C}_{1}$ and ${ }^{13} \mathrm{C}_{2}$ isotopomers, respectively. In positive-ion mode, the HRESIMS contained the pseudomolecular ion at $m / z 427.1596$ [M $+\mathrm{H}^{+}$(calc 427.1604), in addition to a very abundant ion at $m / z 409\left[\mathrm{M}+\mathrm{H}-\mathrm{H}_{2} \mathrm{O}\right]^{+}$showing an aliphatic alcohol. Twenty discrete ${ }^{13} \mathrm{C}$ NMR peaks were evident: $1 \cdot \mathrm{CH}_{3}, 7 \cdot \mathrm{CH}_{2}, 5 \cdot \mathrm{CH}, 7 \cdot \mathrm{C}_{\mathrm{q}}$. Three $\mathrm{C}_{\mathrm{q}}$ were carbonyls, with two coincident ${ }^{13} \mathrm{C}$ NMR signals at $\delta 174.5$ and a singleton at $\delta 173.1$ and IR bands at 1795,1790 , and $1689 \mathrm{~cm}^{-1}$. The higher-frequency $C=0$ absorptions suggested that they were likely to be a cyclic anhydride. As with the other examples, the combined NMR data (Table S3, SI) suggested the neoclerodane skeleton for $\mathbf{1 0}$. However, the upper five-membered ring was unusual, in that it was a succinic anhydride. Carbonyl C-15 resonated at $\delta 174.5$ and $\mathrm{C}-16$ appeared at $\delta 173.1$. The latter showed a 3-bond HMBC correlation with one $\mathrm{H}-14(\delta 2.04)$. COSY then identified the other $\mathrm{H}-14(\delta 1.42)$ and $\mathrm{H}-13$

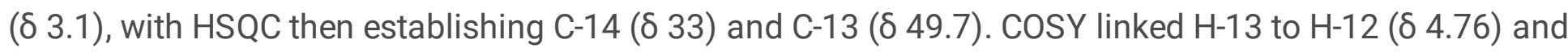
HSQC identified C-12 ( $\delta 65.8)$. A 2-bond HMBC from the latter led to assignment of one $\mathrm{H}-11$ ( $\delta 1.89 \mathrm{dd})$, which was shown by HSQC to be attached to the same carbon $(C-11, \delta 34.2)$ as the signal at $\delta_{H} 2.43$ for the other $\mathrm{H}-11$. An additional 2-bond HMBC led to identification of C-9 $(\delta 36.2)$. In the lower part, a 3-bond HMBC was observed from the methyl H-17 ( $\delta 0.94)$ to $\mathrm{C}-7$ ( $\delta 41.2)$. A 3-bond HMBC from H-8 to the hemiacetal carbon $(\mathrm{C}-6, \delta$ 108.1) confirmed its location. A further HMBC from $\mathrm{C}-6$ to one $\mathrm{H}-18$ ( $\delta 4.34)$ showed the closure of the lower tetrahydrofuran ring / hemiacetal. An MM2-minimised model explained the absence of a HMBC cross-peak from the other $\mathrm{H}-18$ to $\mathrm{C}-6$, in that the dihedral angle is $c a .90^{\circ} . \mathrm{H}-18(\delta$ 4.34) also gave an $\mathrm{HMBC}$ with $\mathrm{C}-3$ ( $\delta 73.3)$, which carries an oxygen. HSQC then identified $\mathrm{H}-3$ ( $\delta 3.83)$ as a dd with $J=9.4,4.6 \mathrm{~Hz}$. The larger coupling constant implies a trans-diaxial coupling; thus $\mathrm{H}-3$ is axial. HMBC correlation from $\mathrm{H}-3$ identified $\mathrm{C} 2$ ( $\delta 32.8$ ). A 2-bond HMBC linked H-3 with C-4. The (C-19)-O-(C$20)$ ester bridge was also confirmed by $\mathrm{HMBC}$, in that both $\mathrm{H}-19$ ( $\delta 4.59$ and $\delta 4.65)$ showed cross-peaks with $\mathrm{C}-5$ ( $\delta$ 85.6), C-6 ( $\delta$ 50.2) and C-20 ( $\delta$ 174.5). C-19 was identified by HSQC at $\delta 68.5$, consistent with the ester. Thus the structure of $\mathbf{1 0}$ (fatimanol $\mathrm{N}$ ) is as in Fig. 1.

Compound 11. Instability under MS conditions precluded obtaining useful mass spectra. The ${ }^{13} \mathrm{C}$ NMR showed discrete peaks for twenty-one carbons: $2 \times \mathrm{CH}_{3}, 6 \times \mathrm{CH}_{2}, 8 \times \mathrm{CH}, 5 \times \mathrm{C}_{\mathrm{q}}$. The IR contained a band 
for $\mathrm{OH}\left(3414 \mathrm{~cm}^{1}\right)$ but no carbonyls were evident. The NMR data (Table S3, SI) showed a neoclerodane structure. The 3-substituted aromatic furan was shown by the downfield resonances of the ring-H. $\mathrm{H}-14$ resonated at $\delta 6.41$, while $\mathrm{H}-15$ and $\mathrm{H}-16$ were co-incident at $\delta 7.43$. $\mathrm{HMBC}$ correlated $\mathrm{H}-14$ with $\mathrm{C}-13$ ( $\delta$ 126.7), $\mathrm{C}-15$ ( $\delta$ 143.6) and C-16 ( $\delta$ 139.3). Similarly, $\mathrm{H}-15$ was correlated with $\mathrm{C}-16$ and $\mathrm{H}-16$ was correlated with $C-14(\delta$ 108.6) and with $C-15$. HMBC was also useful in linking $C-13, C-13$, and $C-16$ with $\mathrm{H}-12(\delta 5.10 \mathrm{~m})$ and HSQC identified $\mathrm{C}-12$ at $\delta$ 71.6. A COSY cross-peak from $\mathrm{H}-12$ to the multiplet signal at $\delta 1.85$ identified the latter as one $\mathrm{H}-11$ and HSQC led to $\mathrm{C}-11(\delta 40.5)$ and thence to the other $\mathrm{H}-11$ ( $\delta$ 2.24). C-20 was an acetal carbon, as shown by its chemical shift ( $\delta 101.2)$, and HSQC identified $\mathrm{H}-20$ as the singlet at $\delta 5.08$. $\mathrm{H}-20$ gave HMBC cross-peaks to $\mathrm{C}-8$ ( $\delta 35.2)$ and $\mathrm{C}-9$ ( $\delta 44.6)$, and to $\mathrm{C}-12$, demonstrating the ether linkage. HMBC from $\mathrm{C}-8$ to both $\mathrm{H}-11$, completed this ring. The $\mathrm{C}-\mathrm{Me}$ group (C-17, $\mathrm{H}-17)$ was readily identified as the origin of the most upfield NMR signals $\left(\delta_{C} 16.3, \delta_{H} 1.02\right)$. From here, a 2-bond HMBC cross-peak identified H-8 $(\delta 1.85)$, confirmed by a COSY cross-peak from H-17. Three-bond $\mathrm{HMBC}$ interactions also identified both $\mathrm{H}-7$ ( $\delta 1.65 \mathrm{t}$ and $\delta 2.36 \mathrm{dd})$. The multiplicities of these indicated that the former was axial and the latter was equatorial. C-7 ( $\delta$ 36.1) was located by HSQC. Acetal C-6 ( $\delta$ 110.9 ) was confirmed by 3 -bond $\mathrm{HMBC}$ with both $\mathrm{H}-19$ ( $\delta 3.94$ and $\delta 4.15$, geminally coupled). Both $\mathrm{H}-19$ also gave HMBC cross-peaks to C-20, confirming the ether bridge between $C-19$ ( $\delta 58.5)$ and $C-20$. The closure of the lower tetrahydrofuran ring was demonstrated by HMBC from C- 6 to both H-18 $(\delta 3.89, \delta$

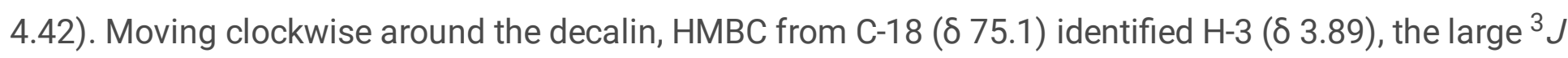
of which indicated a trans-diaxial relationship with one $\mathrm{H}-2$ ( $\delta$ 1.41). Further HMBC, HSQC, and COSY analysis established the assignments of $\mathrm{H}-1$ ( $\delta 1.95$ and $\delta 1.99), \mathrm{C}-1$ ( $\delta 23.2), \mathrm{H}-2$ ( $\delta 1.41$ and $\delta 2.15$ ), $\mathrm{C}-2$ ( $\delta$ 30.3) and C-3 ( $\delta$ 73.2). Thus 11 has the novel polycyclic structure shown in Figure 1, with many fused rings and bridges. Fortunately, these fusions and bridges make the structure fairly rigid and it was straightforward to assign the relative stereochemical configurations by use of coupling constants (Karplus relationship) and NOESY. Figure 2 shows the key NOESY interactions used in this assignment. Particularly useful was the NOE interaction between the methoxy protons and $\mathrm{H}-18_{\text {exo }}$ ( $\delta 3.89$ ), which confirms that the methoxy is on the lower face of the trans-decalin. The name fatimanol 0 is assigned to the novel compound 11 (Figure 1).

Compound 12. HRESIMS gave pseudomolecular ions at $m / z$ 443.1706 $[\mathrm{M}+\mathrm{Na}]^{+}$(calc 443.1682) and $\mathrm{m} / \mathrm{z} 421.1854[\mathrm{M}+\mathrm{H}]^{+}$(calc 421.1862), corresponding to the formula $\mathrm{C}_{22} \mathrm{H}_{28} \mathrm{O}_{8}$. The ${ }^{13} \mathrm{C}$ NMR spectrum showed 22 discrete signals: $2 \cdot \mathrm{CH}_{3}, 6 \cdot \mathrm{CH}_{2}, 8 \cdot \mathrm{CH}, 6 \cdot \mathrm{C}_{\mathrm{q}}$. The NMR data (Table S4, SI) showed that 12 was a neoclerodane. In the upper furan, $\mathrm{C}-13$ resonated at $\delta 126.7$ and gave HMBC cross-peaks to $\mathrm{H}-14$ ( $\delta$ 6.46), $\mathrm{H}-15$ ( $\delta 7.53)$ and $\mathrm{H}-16\left(\delta\right.$ 7.59). The corresponding ${ }^{13} \mathrm{C}$ resonated at $\delta 109.2(\mathrm{C}-14), \delta 145.6(\mathrm{C}-15)$ and $\delta 141.4(\mathrm{C}-16)$. C15 and $\mathrm{C}-16$ were differentiated by a HMBC correlation between the latter and $\mathrm{H}-12$

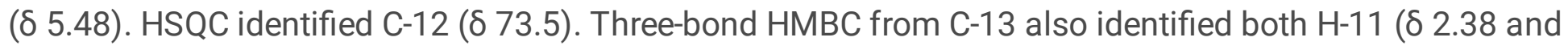
$\delta 2.51)$, from which $\mathrm{C}-11$ was shown to be at $\delta$ 43.6. The downfield $\mathrm{H}-11$ signal also showed HMBC cross-

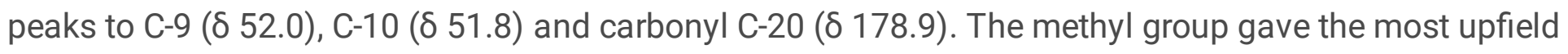
signals (C-17 $\delta 16.9, \mathrm{H}-17 \delta$ 0.99). Strong HMBC cross-peaks identified C-8 ( $\delta 38.65)$ and C-7 ( $\delta 33.5)$, whereas a weak cross-peak suggested the peak at $\delta 74.7$ to be due to $\mathrm{C} 6 . \mathrm{H}-8$ resonated at $\delta 1.78$ and $\mathrm{H}$ - 
7 at $\delta 1.56$ and $\delta$ 2.22. The chemical shifts of $\mathrm{C}-6$ and of $\mathrm{H}-6$ ( $\delta 4.99)$ were consistent with an ester oxygen being attached thereto and $\mathrm{HMBC}$ from $\mathrm{H}-6$ to the carbonyl signal at $\delta 171.6$ confirmed that this appendage was an acetoxy group (AcO-) $\left(\mathrm{MeCO}_{2} \delta_{\mathrm{C}} 21.3 \delta_{\mathrm{H}} 2.04\right)$. $\mathrm{H}-6$ also gave a strong HMBC 2-bond to $\mathrm{C}-5$ ( $\delta 48.0)$ and a cross-peak to $\mathrm{C}-19$ ( $\delta 61.4)$. The diastereotopic $\mathrm{H}-19$ protons gave well-separated doublet signals at $\delta 3.90$ and $\delta$ 4.62. $\mathrm{C}-19$ gave a strong 3-bond $\mathrm{HMBC}$ to $\mathrm{H}-10$ ( $\delta$ 1.89). The upfield $\mathrm{H}-19$ gave a 2-bond HMBC with quaternary C-4 ( $\delta 52.8)$. The relatively upfield chemical shift of C-4 was consistent with the strained oxirane and C-18 (a methylene) was also identified by its chemical shift at $\delta$ 42.5. HSQC then linked it to the doublets for $\mathrm{H}-18(\delta 2.72, \delta 2.80)$. C-18 gave a moderate $\mathrm{HMBC}$ to $\mathrm{H}-3$ ( $\delta$

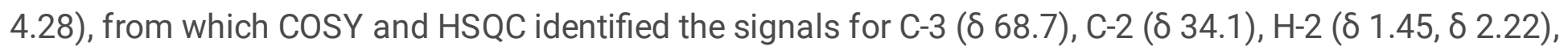
$\mathrm{C}-1$ ( $\delta 23.1)$ and $\mathrm{H}-1(\delta 1.78, \delta 2.12)$. Completing ring $A$, the upfield $\mathrm{H}-1$ gave a strong COSY cross-peak with $\mathrm{H}-10$. The structure of 12 is less rigid than 11 but it was still possible to assign its relative configurations by NOESY (Fig. 2). These data confirm the structure of 12, fatimanol P (Fig. 1).

Compound 13. HRESIMS showed a pseudomolecular ion at $m / z$ 405.1880 $[\mathrm{M}+\mathrm{Na}]^{+}$(calc 405.1889), corresponding to the formula $\mathrm{C}_{20} \mathrm{H}_{30} \mathrm{O}_{7}$. Other ions were observed at $m / z 787.3875[2 \mathrm{M}+\mathrm{Na}]^{+}$(calc 787.3881). Fragment ions were observed at $m / z 729.3844\left[2 \mathrm{M}+\mathrm{Na}-\mathrm{C}_{2} \mathrm{H}_{2} \mathrm{O}_{2}\right]^{+}$(calc 729.3826), $\mathrm{m} / z 711$ $\left[2 \mathrm{M}+\mathrm{Na}-\mathrm{C}_{2} \mathrm{H}_{2} \mathrm{O}_{2}-\mathrm{H}_{2} \mathrm{O}\right]^{+}, m / z 693\left[2 \mathrm{M}+\mathrm{Na}-\mathrm{C}_{2} \mathrm{H}_{2} \mathrm{O}_{2}-2 \times \mathrm{H}_{2} \mathrm{O}\right]^{+}, m / z 347.1850\left[\mathrm{M}+\mathrm{Na}-\mathrm{C}_{2} \mathrm{H}_{2} \mathrm{O}_{2}\right]^{+}$ (calc 347.1834), $m / z 329.1744\left[\mathrm{M}+\mathrm{Na}-\mathrm{C}_{2} \mathrm{H}_{2} \mathrm{O}_{2}-\mathrm{H}_{2} \mathrm{O}\right]^{+}$(calc 329.1729), and $m / z 311.1639[\mathrm{M}+\mathrm{Na}-$ $\left.\mathrm{C}_{2} \mathrm{H}_{2} \mathrm{O}_{2}-2 \times \mathrm{H}_{2} \mathrm{O}\right]^{+}$(calc 311.1623), indicating the presence of at least two hydroxy groups. In the negative-ion HRESIMS, confirmatory peaks were seen at $m / z 427.1970$ [M + formate $]^{-}$(calc 427.1968), $\mathrm{m} / \mathrm{z} 417.1689\left[\mathrm{M}+{ }^{35} \mathrm{Cl}\right]^{-}$(calc 417.1680), and $\mathrm{m} / z 381.1920[\mathrm{M}-\mathrm{H}]^{-}$(calc 381.1913). The ${ }^{13} \mathrm{C} \mathrm{NMR}$ spectrum contained signals for twenty carbons: $1 \cdot \mathrm{CH}_{3}, 7 \cdot \mathrm{CH}_{2}, 8 \cdot \mathrm{CH}$, and $4 \cdot \mathrm{C}_{\mathrm{q}}$, although two signals were co-incident at $\delta 143.5$.

The NMR data (Table S4, SI) suggested that 13 had a structure broadly similar to those of the neoclerodanes but with important differences. The upper ring was a furan, with ${ }^{1} \mathrm{H}$ NMR signals at $\delta 6.48$ $(\mathrm{H}-14), \delta 7.56(\mathrm{H}-15)$ and $\delta 7.50(\mathrm{H}-16)$. The signals for $\mathrm{H}-15$ and $\mathrm{H}-16$ were differentiated through COSY from $\mathrm{H}-15$ to $\mathrm{H} 14$ and by $\mathrm{HMBC}$ from $\mathrm{H}-16$ to $\mathrm{C}-12$ ( $\delta 62.1)$. HSQC then linked these to the ${ }^{13} \mathrm{C}$ peaks at $\delta$ 109.7 (C-14) and $\delta 143.5$ (C-15, C-16). HMBC from $\mathrm{H}-14, \mathrm{H}-15$, and $\mathrm{H} 16$ then identified the ${ }^{13} \mathrm{C}$ signal at $\delta$ 132.4 as being due to $\mathrm{C}-13$. $\mathrm{HMBC}$ from $\mathrm{C} 13, \mathrm{C}-14$ and $\mathrm{C}-16$ to the ${ }^{1} \mathrm{H}$ signal at $\delta 4.68$, along with HSQC from $\mathrm{C}-12$, identified this multiplet signal as $\mathrm{H}-12$. This chemical shift suggested that this proton was benzylic and it gave COSY cross-peaks to $12-\mathrm{OH}$ ( $\delta 5.02$, doublet) and both $11-\mathrm{H}(\delta 1.60, \delta 2.01$, both dd). HSQC from the latter then gave 11-C ( $\delta 41.7)$. Linkage of this upper side-chain to the core bicycle was demonstrated by a HMBC correlation from $\mathrm{H}-12$ to $\mathrm{C}-9\left(\delta 40.4, \mathrm{C}_{\mathrm{q}}\right)$ and by HMBC from both $\mathrm{H}-11$ to $\mathrm{C}-8$ ( $\delta$ 35.6) and to $\mathrm{C}-10(\delta 51.5)$. The 3-bond HMBC cross-peak between $\mathrm{H}-11$ ( $\delta 1.60)$ and $\mathrm{C}-8$ was weak, owing to the dihedral angle $(\mathrm{H}-11)-(\mathrm{C}-11)-(\mathrm{C}-9)-(\mathrm{C}-8)$ being close to $90^{\circ} . \mathrm{H}-8(\delta 1.47)$ also gave a HMBC crosspeak with $\mathrm{C}-11$. The other side-chain at $\mathrm{C}-9$ was a hydroxymethyl $\left(\mathrm{HOCH}_{2}-\right)$ unit, with $\mathrm{C}-20(\delta 53.3)$ giving weak $\mathrm{HMBC}$ with both $\mathrm{H}-11$. The geminal protons $\mathrm{H}-20$ ( $\delta 3.21$ and $\delta 3.32)$ gave strong COSY cross-peaks with each other and with HO-20 ( $\delta$ 4.46). The methyl group was at C-8, as shown by a COSY cross-peak 
from $\mathrm{H}-8$ to the doublet signal at $\delta 0.71(\mathrm{H}-17)$, from which HSQC identified the ${ }^{13} \mathrm{C}$ peak at $\delta 16.3$ as $\mathrm{C}$ 17. Moving clockwise around the cyclohexane B-ring, a strong 2-bond $\mathrm{HMBC}$ from $\mathrm{C}-8$ identified $\mathrm{H}_{\mathrm{ax}}-7$ at $\delta$ $1.21(\mathrm{q}, J=11 \mathrm{~Hz}$ ). HSQC revealed $\mathrm{C}-7$ ( $\delta 37.9)$ and thence $\mathrm{H}_{\mathrm{eq}}{ }^{-7}(\delta 1.47)$. Both $\mathrm{H}-7$ gave strong 2-bond HMBC correlations with C-6 ( $\delta 69.4)$, from which HSQC showed the signal at $\delta 3.36$ as being $\mathrm{H}-6$. The COSY cross-peak from $\mathrm{H}_{\mathrm{ax}}-7$ to $\mathrm{H}-6$ was strong, whereas that from $\mathrm{H}_{\mathrm{eq}}-7$ to $\mathrm{H}-6$ was much weaker, suggesting that the dihedral angle $\left(\mathrm{H}_{\mathrm{eq}}-7\right)-(\mathrm{C}-7)-(\mathrm{C}-6)-(\mathrm{H}-6)$ was $c a .90^{\circ}$ and thus that $\mathrm{H}-6$ was axial. COSY linked H-6 to HO-6 ( $\delta$ 4.46). Three-bond HMBC correlations from both $\mathrm{H}-7$ located quaternary $\mathrm{C}-5$ ( $\delta$ 59.8). Ring $B$ was completed by observation of a 2-bond HMBC cross-peak from $\mathrm{C}-5$ to $\mathrm{H}-10$ ( $\delta 2.07)$.

Establishing ring A was more challenging. A 2-bond $\mathrm{HMBC}$ cross-peak from $\mathrm{H}-10$ identified $\mathrm{C}-1$ at $\delta 24.6$, from which HSQC showed that the $\mathrm{H}-1$ signals were at $\delta 1.87$ and $\delta$ 1.98. A strong 3-bond HMBC linked $\mathrm{C}$ 10 with one $\mathrm{H}-2$ signal $(\delta 1.87)$, whereas the cross-peak to the other $\mathrm{H}-2(\delta 1.27)$ was weaker. A 3-bond HMBC cross-peak was also seen linking $\mathrm{H}-1(\delta 1.27)$ to $\mathrm{C}-5$; the 3-bond path between these two nuclei cannot pass through C-1 and C-10, thus ring A must be five-membered. Quaternary C-3 ( $\delta 57.7)$ was identified through a 2-bond $\mathrm{HMBC}$ with $\mathrm{H}-2(\delta 1.27)$ and a 3-bond correlation with $\mathrm{H}-10$, completing the cyclopentane. Three-bond HMBC from both $\mathrm{H}-2$ showed the methylene $\mathrm{C}-4(\delta 62.5)$ as being attached at $\mathrm{C}-3$ and the $\mathrm{H}-4$ protons were observed as $\mathrm{dd}$ at $\delta 3.27$ and $\delta 3.66$. These $\mathrm{H}-4$ signals were linked by COSY to each other and to HO-4 ( $\delta 4.46)$. A 2-bond HMBC correlation between $\mathrm{H}-4$ ( $\delta 3.27)$ and $\mathrm{C}-3$ confirmed the attachment of the $\mathrm{HOCH}_{2}$ - A 2-bond $\mathrm{HMBC}$ from C-3 and a 3-bond cross-peak from $\mathrm{H}-2$ ( $\delta$ 1.27) revealed the other substituent at quaternary $\mathrm{C}-3$ by identifying $\mathrm{C}-18(\delta 102.0)$. The hemiacetal was confirmed by a COSY from H-18 ( $\delta 4.76)$ to HO-18 ( $\delta 6.26)$. HMBC from C-5, C-6 and C-10 to the doublet signals at $\delta 3.80$ and $\delta 3.87$ identified both $\mathrm{H}-19$. C-19 $(\delta 67.3)$ was shown to be a methylene by HSQC and 135DEPT. The chemical shifts of $\mathrm{C}-19$ and both $\mathrm{H}-19$ suggested the attachment of an oxygen but this was not an $\mathrm{OH}$ (no COSY cross-peak). However, HMBC linked C-19 with $\mathrm{H}-18$ and $\mathrm{C}-18$ with both $\mathrm{H}-$ 19. The only structure consistent with these connectivities is the lactol / cyclic acetal shown. It was not possible to obtain a good NOESY spectrum, so the relative configuration shown in Chart 1 is speculative, except where suggested by ${ }^{3} J_{\mathrm{H}-\mathrm{H}}$ coupling constants. The NMR spectra contained a second (smaller) set of peaks, which we ascribe to the presence of a minor diastereoisomer in slow equilibrium, probably the epimer at the acetal C-18. Thus 13 (fatimanol Q) has the novel structure shown in Fig. 1.

Compound 14. HRESIMS showed a pseudomolecular ion $m / z$ 447.1985 [M + Na] $]^{+}$(calc 447.1995), consistent with the molecular formula $\mathrm{C}_{22} \mathrm{H}_{32} \mathrm{O}_{8}$. Additional ions were seen at $\mathrm{m} / z 871.4083[2 \mathrm{M}+\mathrm{Na}]^{+}$ (calc 871.4091) and $\mathrm{m} / \mathrm{z} 425.2167\left[\mathrm{M}+\mathrm{H}^{+}\right.$(calc 425.2175) in positive-ion mode, and $469.2075[\mathrm{M}+$

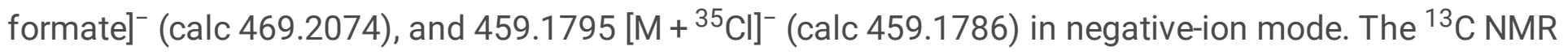
spectrum (in $\left(\mathrm{CD}_{3}\right)_{2} \mathrm{SO}$ ) contained discrete signals for twenty-two carbon atoms: $2 \cdot \mathrm{CH}_{3}, 7 \cdot \mathrm{CH}_{2}, 8 \cdot \mathrm{CH}, 5$ $\cdot \mathrm{C}_{\mathrm{q}}$

Combined analysis of the NMR data $\left(\left(\mathrm{CD}_{3}\right)_{2} \mathrm{SO}\right.$, Table $\left.\mathrm{S} 4, \mathrm{SI}\right)$ showed that 14 was a conventional neoclerodane. The upper ring was a furan, with ${ }^{1} \mathrm{H}$ signals for $\mathrm{H}-14(\delta 6.42), \mathrm{H}-15(\delta 7.56)$ and $\mathrm{H}-16(\delta$ 


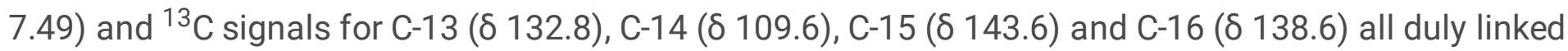
by HSQC and HMBC. Strong 3-bond HMBC cross-peaks were evident from H-12 ( $\delta 4.59)$ to C-14 and C-16. HSQC linked this proton to $\mathrm{C}-12$ ( $\delta$ 61.7), which also gave HMBC cross-peaks to $\mathrm{H}-14$ and $\mathrm{H}-16$. A 2-bond $\mathrm{HMBC}$ from $\mathrm{H}-12$ identified $\mathrm{C}-11$ ( $\delta 39.7$ ), from which both $\mathrm{H}-11$ ( $\delta 1.67$ and $\delta 1.86$ ) could be identified by HSQC. HO-12 ( 8 4.90) was located through a 3-bond HMBC from C-11. A 3-bond HMBC from H-12 identified quaternary $\mathrm{C}-9$ ( $\delta 43.3)$, while a similar correlation from $\mathrm{H}-11$ ( $\delta 1.67)$ confirmed C-10 ( $\delta 46.8)$ and thence $\mathrm{H}-10$ ( $\delta$ 1.96). From here, $\mathrm{C}-20$ ( $\delta$ 63.0) was located by $\mathrm{HMBC}$ to $\mathrm{H}-10$; the $\mathrm{H}-20$ protons were approximately co-incident at $\delta 3.28$, with HMBC cross-peaks to C-9 (weak, 2-bond), C-10, and C-11. Twobond HMBC linked C-10 to both $\mathrm{H}-1$ ( $\delta 1.75$ and $\delta 2.00)$, from which $\mathrm{C}-1$ ( $\delta 21.5)$ was identified by HSQC. The upfield $\mathrm{H}-1$ signal gave a weak 2-bond HMBC with $\mathrm{C}-2$ ( $\delta 34.5)$, whereas the downfield $\mathrm{H}-1$ signal correlated strongly with $C-3(\delta 65.0)$. The signal at $\delta 1.17$ was a double quartet $(J=4,11 \mathrm{~Hz})$, indicating that this was due to $\mathrm{H}-2_{\mathrm{ax}}$, while $\mathrm{H}-2_{\text {eq }}$ resonated as a narrow multiplet at $\delta 1.91$. Thus the coupling to $\mathrm{H}-3$ ( $\delta$ 3.80) shows that this proton is axial / down) and $\mathrm{HO}-3$ is equatorial / up. Furthermore, both $\mathrm{H}-3$ and $\mathrm{H}-$ 10 are axial, showing that ring $A$ is in the chair conformation. A 2-bond $\mathrm{HMBC}$ correlation from $\mathrm{H}-3$ identified C-4 ( $\delta 70.0)$ and a 3-bond correlation revealed C-18 ( $\delta 43.0)$. The $\mathrm{H}-18$ protons resonated as doublets at $\delta 2.83$ and $\delta 3.06$; the chemical shifts suggested the spiro-oxirane ring. Strong HMBC crosspeaks from these protons were observed to $\mathrm{C}-4$ and $\mathrm{C}-5$ (845.47). An $\mathrm{AcOCH}_{2}$ - group was present at $\mathrm{C}-5$, as demonstrated by HMBC from both $\mathrm{H}-19(\delta 4.40, \delta 4.57)$ to $\mathrm{C}-4$ and $\mathrm{C}-5$. These protons also correlated with the ester carbonyl $\mathrm{MeCO}_{2}-19$ ( $\delta$ 170.8), with the adjacent methyl group $\left(\mathrm{MeCO}_{2}-19\right)$ resonating at $\delta_{\mathrm{H}}$ $2.01 / \delta_{C} 21.5$. Three-bond HMBC cross-peaks were also seen from both $\mathrm{H}-19$ to $\mathrm{C}-6$ ( $\delta$ 73.3) and HSQC then located the $\mathrm{H}-6$ signal at $\delta 3.62(\mathrm{brd}, J=c a .11 \mathrm{~Hz})$. The $\mathrm{H}-6$ signal was better resolved when the ${ }^{1} \mathrm{H}$ NMR spectrum was obtained on a solution in $\mathrm{CDCl}_{3}$, which showed it as $\delta 3.70$ (dd, $J=10.0,6.0 \mathrm{~Hz}$ ). The larger axial-axial coupling shows that $\mathrm{H}-6$ is axial and up on the trans-decalin. Both $\mathrm{H}-7(\delta 1.39, \delta 1.52)$ were located both by HSQC with C-7 and by HMBC with C-6, whence C-7 ( $\delta 34.7)$ was revealed by HSQC. $\mathrm{H}-7$ also formed $\mathrm{HMBC}$ correlations with the methyl $\mathrm{C}-17$ ( $\delta 17.0)$, from which $\mathrm{H}-17$ was identified at $\delta$ 0.82. Completing ring $\mathrm{B}, \mathrm{H}-17$ gave an $\mathrm{HMBC}$ cross-peak with $\mathrm{C}-9$. These spectroscopic interpretations were aided, in part, by ${ }^{1} \mathrm{H}, \mathrm{COSY}$ and $\mathrm{HSQC}$ spectra of a solution in $\mathrm{CDCl}_{3}$, which were better resolved, although paucity of sample precluded identification of the quaternary carbons (Table S4). Examination of the coupling constants allowed confirmation of the trans-decalin structure and the relative configurations of most of the substituents, although the relative configuration at $\mathrm{C}-12$ could not be established. We assign the novel structure shown in Fig. 1 to 14, fatimanol R.

Compound 15. The HRESIMS contained a pseudomolecular ion at $m / z 379.1748[\mathrm{M}+\mathrm{H}]^{+}$(calc 379.1757) which showed the formula $\mathrm{C}_{20} \mathrm{H}_{26} \mathrm{O}_{7}$. Other ions were observed at $m / z 779.3248[2 \mathrm{M}+\mathrm{Na}]^{+}$(calc 779.3255), $m / z 401.1567[\mathrm{M}+\mathrm{Na}]^{+}$(calc 401.1576), $m / z 361.1642\left[\mathrm{M}+\mathrm{H}-\mathrm{H}_{2} \mathrm{O}\right]^{+}$(calc 361.1651), $343.1537\left[\mathrm{M}+\mathrm{H}-2 \times \mathrm{H}_{2} \mathrm{O}\right]^{+}$(calc 343.1546), and $\mathrm{m} / z 325.1341\left[\mathrm{M}+\mathrm{H}-3 \times \mathrm{H}_{2} \mathrm{O}\right]^{+}$(calc 325.1440). The latter three fragment ions indicated the presence of three hydroxy groups. Negative ions were present at $\mathrm{m} / \mathrm{z}$ 423.1656 [M + formate $]^{-}$(calc 423.1655), and $\mathrm{m} / \mathrm{z} 377.1605[\mathrm{M}-\mathrm{H}]^{-}$(calc 377.1600). The ${ }^{13} \mathrm{C} \mathrm{NMR}$ spectrum (in $\left(\mathrm{CD}_{3}\right)_{2} \mathrm{SO}$ ) contained individual signals for twenty carbon atoms: $1 \cdot \mathrm{CH}_{3}, 6 \cdot \mathrm{CH}_{2}, 8 \cdot \mathrm{CH}, 5$. 
$\mathrm{C}_{\mathrm{q}}$. The NMR data (Table S5, SI) for 15 indicated a conventional neoclerodane. The upper furan showed

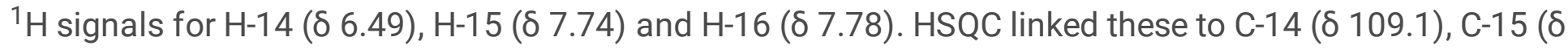
$145.0)$ and $C-16(\delta 141.1)$, respectively. The $C-13{ }^{13} \mathrm{C}$ NMR signal was identified at $\delta 125.6$ by HMBC. Moving south, 3-bond $\mathrm{HMBC}$ cross-peaks from $\mathrm{C}-14$ and $\mathrm{C}-16$ identified $\mathrm{H}-12$ as a triplet at $\delta 5.43$. The HMBC from $\mathrm{C}-16$ to $\mathrm{H}-12$ and the NOESY interaction between $\mathrm{H}-16$ and $\mathrm{H}-12$ distinguished $\mathrm{H}-16$ from $\mathrm{H} 15$. The chemical shift of $\mathrm{H}-12$ strongly suggested that it carried a lactone oxygen, confirmed by HMBC from $\mathrm{H}-12$ to the signal at $\delta 177.0$ (C-20). HSQC linked $\mathrm{H}-12$ to $\mathrm{C}-12$ ( $\delta$ 71.4). A 2-bond HMBC linked H-12 to $\mathrm{C}-11$ ( $\delta 41.2)$, with HSQC from this signal the $\mathrm{H}-11$ protons $(\delta 2.25, \delta 2.45)$. Both $\mathrm{H}-11$ gave $\mathrm{HMBC}$ correlations to the lactone carbonyl C-20, further confirming the ring. Both $\mathrm{H}-11$ also gave HMBC crosspeaks to the quaternary carbon signal at $\delta 51.2$, which was shown to be $C-9$, where the spiro-lactone joins the decalin. Working clockwise around the lower decalin, C-19 gave a strong HMBC to the methyl $\mathrm{H}-17$ protons $(\delta 0.91)$, from which $\mathrm{C}-17$ ( $\delta$ 16.9) was identified. A 2-bond HMBC from H-17 located C-8 ( $\delta 37.3)$ and a 3-bond correlation located the methylene C-7 ( $\delta 34.9)$, HSQC then showed H-8 ( $\delta$ 1.62) and both H-7 (ठ $\left.1.48\left(\mathrm{H}-7_{\mathrm{eq}}\right), \delta 1.96\left(\mathrm{H}-7_{\mathrm{ax}}\right)\right)$. C-7 showed a 2-bond $\mathrm{HMBC}$ with $\mathrm{H}-6$ ( $\left.\delta 3.67\right)$; this chemical shift indicates an attached alcohol. C-6 ( $\delta 72.5)$ was shown by HMBC with $\mathrm{H}-7$ eq and HSQC with $\mathrm{H}-6$. The signal for 6$\mathrm{OH}$ was broad but gave HMBC correlation with C-6. The signal at $\delta 46.4$ was due to $\mathrm{C}-5$. HMBC interactions then tied $\mathrm{C}-5$ to the attached $\mathrm{CH}_{2} \mathrm{OH}$ group ( $\mathrm{H}-19 \delta 3.69, \delta 4.36 ; \mathrm{HO}-19 \delta 4.07$ ) and HSQC identified C-19 ( $\delta$ 59.3). Both H-19 gave strong 3-bond HMBC cross-peaks to quaternary C-4 ( 6 68.8), which was shown to be part of a spiro-oxirane. In the oxirane, $\mathrm{H}-18_{\text {left }}$ resonated as a doublet at $\delta 2.69$ and $\mathrm{H}-18_{\text {right }}$ as a doublet at $\delta 2.89$. These diastereotopic protons were distinguished by NOESY

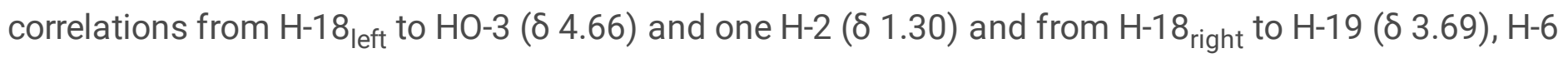
and HO-6. Three-bond HMBC from both H-18 identified C-3 ( $\delta 64.3)$, from which H-3 ( $\delta 4.19)$ was shown by HSQC. HMBC from C-3 identified its HO-3 as a doublet at $\delta 4.66$. The ring was completed by

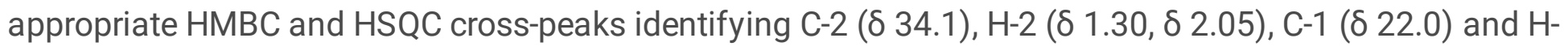
$1(\delta 1.59, \delta 1.96)$. Finally, there was a strong HMBC linking $\mathrm{H}-2$ ( $\delta 1.30)$ with $\mathrm{C}-10(\delta 51.2)$, closing the ring. $\mathrm{H}-10$ resonated at $\delta 1.67$.

The relative configurations were largely demonstrated by NOESY spectroscopy, with some consideration of ${ }^{1} \mathrm{H} J$ values. Firstly, a strong NOESY interaction was seen between $\mathrm{H}-16$ and $\mathrm{H}-17$ and a weaker one between $\mathrm{H}-14$ and $\mathrm{H}-17$. This demonstrates that the furan and the methyl group are on the same face of the lactone and that the configuration at $\mathrm{C}-12$ is $S$. The signal for $\mathrm{H}-7(\delta 1.48)$ is a broad doublet, thus this proton is equatorial up as the only large coupling constant would be ${ }^{2} J_{\text {gem }}$ to $\mathrm{H}-7$ ax $(\delta 1.96)$. The methyl $(\mathrm{C}-17, \mathrm{H}-17)$ is equatorial down, as for the vast majority of neoclerodanes. $\mathrm{H}-7$ ax makes a strong NOESY interaction with $\mathrm{H}-19$ ( $\delta 4.36$ ), consistent with $\mathrm{C}-19$ being axial down. HO-6 is located on the lower face of the decalin, as $\mathrm{H}-6$ experiences a strong NOESY correlation with $\mathrm{H}-7$ eq on the upper face. Running the spectrum in DMSO also allowed a NOESY interaction between HO-6 and $\mathrm{H}-19(\delta 4.36)$, confirming the orientation of HO-6. The configuration at C-4 of the spiro-oxirane was determined. $\mathrm{H}-1$ ( $\delta 1.59)$ is axial and down, as it has three large coupling constants (trans-diaxial to $\mathrm{H}-10$ and $\mathrm{H}-2(\delta 1.30)$ and geminal to $\left.\mathrm{H}-1_{\text {eq }}(\delta 1.96)\right)$. Therefore, $\mathrm{H}-2(\delta 1.30)$ is axial up. $\mathrm{H}-18_{\text {left }}(\delta 2.69)$ makes strong NOESY contacts with $\mathrm{H}-$ 
$2 \mathrm{ax}$ and with $\mathrm{HO}-4$ (upper face), which shows that the $\mathrm{CH}_{2}$ of the oxirane is on the upper face, as in $\mathbf{2 , 8 , 9}$, and 12. Finally, $\mathrm{H}-10$ is on the upper face, as it shows a trans-diaxial coupling to $\mathrm{H}-1_{\mathrm{ax}}$. Thus the bicycle is a trans-decalin. These spectroscopic assignments were aided partly by ${ }^{1} \mathrm{H}, \mathrm{COSY}$, and HSQC spectra obtained of a solution in $\mathrm{CDCl}_{3}$, which were better resolved, although shortage of sample precluded identification of the quaternary carbons (Table S5). Minor differences in chemical shift were seen for $\mathrm{H}$ $2_{\text {eq }}, \mathrm{H}-3, \mathrm{H}-14, \mathrm{H}-15, \mathrm{H}-18$, and $\mathrm{H}-19$, probably reflecting minor changes in hydrogen-bonding and consequent minor changes in conformation. The COSY spectrum confirmed the $\mathrm{H}-\mathrm{H}$ connectivities within the molecule. We assign the novel structure shown in Fig. 1 to 15, fatimanol S.

Compound 16. The HRESIMS contained a pseudomolecular ion at $m / z 379.1748[\mathrm{M}+\mathrm{H}]^{+}$(calc 379.1757), consistent with the formula $\mathrm{C}_{20} \mathrm{H}_{26} \mathrm{O}_{7}$. lons were also seen at $m / z 779.3250[2 \mathrm{M}+\mathrm{Na}]^{+}$(calc 779.3255), $\mathrm{m} / \mathrm{z} 401.1568[\mathrm{M}+\mathrm{Na}]^{+}$(calc 401.1576), 361.1643 [M+ $\left.\mathrm{H}-\mathrm{H}_{2} \mathrm{O}\right]^{+}$(calc 361.1651), and $\mathrm{m} / \mathrm{z}$ $325.1432\left[\mathrm{M}+\mathrm{H}-3 \times \mathrm{H}_{2} \mathrm{O}\right]^{+}$(calc 325.1440), indicating three hydroxy groups. The ${ }^{13} \mathrm{C}$ NMR spectrum (in $\left(\mathrm{CD}_{3}\right)_{2} \mathrm{SO}$ ) contained signals for twenty carbon atoms: $1 \cdot \mathrm{CH}_{3}, 6 \cdot \mathrm{CH}_{2}, 8 \cdot \mathrm{CH}$, and $5 \cdot \mathrm{C}_{\mathrm{q}}$. Therefore, 16 is a closely structurally related isomer of 15 . Analysis of the COSY, HSQC, HMBC and some NOESY connectivities showed an identical network to 15 , strongly suggesting that they were stereoisomers. The NMR signals (in $\left(\mathrm{CD}_{3}\right)_{2} \mathrm{SO}$, Table $\left.\mathrm{S} 5, \mathrm{SI}\right)$ for the lower part of the structure were very similar: position-2 $\left(\delta_{\mathrm{H}}\right.$ $\left.1.20, \delta_{H} 2.00, \delta_{C} 34.1\right)$, position-3 $\left(\delta_{H} 4.16, \delta_{C} 64.5\right)$, position-4 $\left(\delta_{C} 68.8\right)$, position-5 $\left(\delta_{C} 46.2\right)$ and position-6 $\left(\delta_{H} 3.65, \delta_{C} 72.5\right)$. However, slightly more significant differences in chemical shift were observed for the upper and right parts of the decalin, at position- $1\left(\delta_{H} 1.43, \delta_{H} 1.68, \delta_{C} 21.5\right)$, position-7 $\left(\delta_{H} 1.42, \delta_{H} 1.74, \delta_{C} 35.6\right)$, position-8 $\left(\delta_{H} 1.74, \delta_{C} 40.0\right)$, and position-10 $\left(\delta_{H} 1.50, \delta_{C} 49.2\right)$. The signal for C-9 ( $\delta$ 51.5) was identical in 16 and 15. Moving into the upper spiro-lactone, the differences were again observed for position-11 $\left(\delta_{H} 2.33, \delta_{H} 2.41, \delta_{C} 42.6\right)$ but less significant for position-12 $\left(\delta_{H} 5.42, \delta_{C} 71.3\right)$ and the lactone carbonyl C-20 $\left(\delta\right.$ 176.8). Small differences were also seen for the furan: position-13 $\left(\delta_{C}\right.$ $125.8)$, position-14 $\left(\delta_{H} 6.51, \delta_{C} 109.3\right)$, position- $15\left(\delta_{H} 7.71, \delta_{C} 145.0\right)$ and position- $16\left(\delta_{H} 7.77, \delta_{C}\right.$ 140.7). The larger differences were in the upper part of the decalin and in the lactone, which suggested that the stereochemical difference between 16 and 15 was at C-9 or at C-12. A detailed study of NOESY data in that area was undertaken. Firstly, the equatorial methyl $\mathrm{H}-17$ gave a strong NOESY cross-peak to $\mathrm{H}-12$, suggesting that these were on the same face of the $\mathrm{Y}$-lactone. Secondly, $\mathrm{H}-12$ gave a strong NOESY correlation with one $\mathrm{H}-11$ ( $\delta 2.41$ ) but only weakly with the other $\mathrm{H}-11$ ( $\delta 2.33)$. Since the furan protons $\mathrm{H}-$ 14 and $\mathrm{H}-16$ both formed strong NOESY cross-peaks with $\mathrm{H}-11$ ( $\delta 2.33$ ), the furan and this upfield $\mathrm{H}-11$ must be on the same face of the $\mathrm{y}$-lactone and this face must be opposite to that carrying $\mathrm{H}-12$. These data are consistent with $\mathbf{1 6}$ having the opposite configuration at C-12 from 15. Other NOESY interactions, COSY cross-peaks and ${ }^{1} \mathrm{H}-{ }^{1} \mathrm{H}$ coupling constants in the decalin were consistent with trans-configuration. The spectroscopic assignments were aided, in part, by ${ }^{1} \mathrm{H}, \mathrm{COSY}$, and HSQC spectra of a solution in $\mathrm{CDCl}_{3}$, which were better resolved, although shortage of sample precluded identification of the quaternary carbons and NOESY data could not be obtained. We assign the novel structure shown in Fig. 1 to 16, fatimanol T. 
Compound 17. The HRESIMS contained a pseudomolecular ion at $m / z 503.1886[\mathrm{M}+\mathrm{Na}]^{+}$(calc 503.1893), confirming the formula $\mathrm{C}_{24} \mathrm{H}_{32} \mathrm{O}_{10}$. Other positive ions at $m / z 983.3881[2 \mathrm{M}+\mathrm{Na}]^{+}$(calc 983.3889), $m / z 481[\mathrm{M}+\mathrm{H}]^{+}, m / z 463.1961\left[\mathrm{M}+\mathrm{H}-\mathrm{H}_{2} \mathrm{O}\right]^{+}$(calc 463.1968), $m / z 445.1856[\mathrm{M}+\mathrm{H}-2 \times$ $\left.\mathrm{H}_{2} \mathrm{O}\right]^{+}$(calc 445.1862), $m / z 421[\mathrm{M}+\mathrm{H}-\mathrm{AcOH}]^{+}, m / z 403.1750\left[\mathrm{M}+\mathrm{H}-\mathrm{H}_{2} \mathrm{O}-\mathrm{AcOH}\right]^{+}$(calc 403.1757), and $\mathrm{m} / \mathrm{z} 361.1644[\mathrm{M}+\mathrm{H}-2 \times \mathrm{AcOH}]^{+}$(calc 361.1651) confirmed the formula and indicated at least two hydroxy groups and at least two acetate esters. Negative-mode ions confirming the formula were present at $\mathrm{m} / z$ 525.1974 [M + formate] $]^{-}$(calc 525.1972), $\mathrm{m} / z 515.1693\left[\mathrm{M}+{ }^{35} \mathrm{Cll}\right]^{-}$(calc 515.1684), and $\mathrm{m} / \mathrm{z}$ 479.1923 [M - H] $]^{-}$(calc 479.1917). The ${ }^{13} \mathrm{C}$ NMR spectrum (in $\left(\mathrm{CD}_{3}\right)_{2} \mathrm{SO}$ ) contained individual signals for twenty-four carbon atoms: $3 \cdot \mathrm{CH}_{3}, 6 \cdot \mathrm{CH}_{2}, 8 \cdot \mathrm{CH}, 7 \cdot \mathrm{C}_{\mathrm{q}}$. Compound 17 was a conventional neoclerodane. As for 15, the upper part of the structure was a furan linked to a y-lactone. $\mathrm{H}-14, \mathrm{H}-15$, and $\mathrm{H}-16$ resonated at $\delta 6.51, \delta 7.71$ and $\delta 7.79$, respectively, with the carbon signals at $\delta 109.1$ (C-14), $\delta$ 144.9 (C-15) and $\delta 141.2$ (C-16) (Table S6, SI). C-13 ( $\delta$ 125.7) was identified through HMBC interactions with $\mathrm{H}-15$ and $\mathrm{H}-16$. $\mathrm{HMBC}$ from $\mathrm{H}-16$ also revealed $\mathrm{C}-12$ ( $\delta 74.1$ ), from which $\mathrm{H}-12$ ( $\delta 5.45)$ was shown by HSQC. COSY then linked H-12 to both $\mathrm{H}-11$ ( $\delta 2.32$ and $\delta 2.45$ ) and thence by HSQC to C-11 ( $\delta 43.1$ ). The chemical shift of $\mathrm{H}-12$ confirmed the lactone and 3-bond HMBC from both $\mathrm{H}-12$ identified the lactone carbonyl C-20 at $\delta$ 177.1. The lactone was tied to the decalin through $\mathrm{HMBC}$ from the upfield $\mathrm{H}-11$ to $\mathrm{C}-8$ ( $\delta$ 37.7). $\mathrm{H}-8$ resonated at $\delta 1.70$ and this signal correlated in $\mathrm{HMBC}$ with the methyl group $(\mathrm{H}-17 \delta 0.96$, C-17 $\delta$ 16.8). Strong HMBC cross-peaks linked $\mathrm{C}-17$ to both $\mathrm{H}-7(\delta 1.54, \delta 1.87)$ and thence by HSQC to $\mathrm{C}$ 7 ( $\delta 36.1)$. HMBC from $\mathrm{H}-8$ and both $\mathrm{H}-7$ to the signal at $\delta 72.8$ identified the latter as $\mathrm{C}-6$, with the chemical shift indicating an oxygen. $\mathrm{H}-6(\delta 4.20)$ gave HMBC correlations to the quaternary $\mathrm{C}-5(\delta 48.2)$ and C-4 ( $\delta$ 76.9). The downfield chemical shift of C-4 indicated an oxygen but contraindicated a spirooxirane. $\mathrm{H}-19$ of the pendant methylene resonated as a pair of geminally coupled doublets at $\delta 4.77$ and $\delta 4.86$, which were linked by $\mathrm{HMBC}$ to $\mathrm{C}-5$ and $\mathrm{C}-4$. The chemical shifts of $\mathrm{H}-19$ suggested an AcO-group and this was confirmed by $\mathrm{HMBC}$ to the ester carbonyl $19-\mathrm{MeCO}_{2}$, which linked onwards to the acetate methyl $\left(\delta_{\mathrm{H}} 2.00, \delta_{\mathrm{C}} 169.9\right)$. $\mathrm{H}-18$ / $\mathrm{C}-18$ is a pendant $\mathrm{HOCH}_{2}$ - group, with 2-bond $\mathrm{HMBC}$ from both $\mathrm{H}-18(\delta$ 3.73 and $\delta 4.04$ ) to $\mathrm{C}-4$ and 3-bond cross-peaks to C-5. Both $\mathrm{H}-18$ resonated as dd, with ${ }^{2} \mathrm{~J}=10 \mathrm{~Hz}$ and smaller couplings to HO-18 ( $\delta$ 5.06). This spin-set was confirmed by COSY. A 3-bond HMBC identified C-3

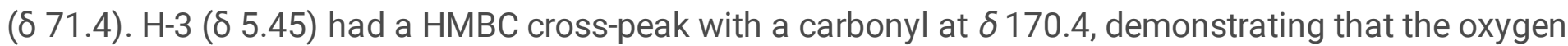
at $\mathrm{C}-3$ was acetylated. The methylenes at position-2 and position- 1 were also identified by application of HMBC, (C-2 $\delta 36, \mathrm{H}-2 \delta 1.80, \delta 2.45 ; \mathrm{C}-1 \delta 22.6, \mathrm{H}-1 \delta 1.95, \delta 2.0)$. The closure of the decalin system was confirmed by a weak HMBC from C-2 to $\mathrm{H}-10(\delta 1.80)$ and a strong peak from $\mathrm{C}-4$ to $\mathrm{H}-10$. The above spectroscopic assignments were aided by ${ }^{1} \mathrm{H}, \mathrm{COSY}, \mathrm{HSQC}$, and $\mathrm{HMBC}$ spectra of a solution in $\mathrm{CDCl}_{3}$, which were better resolved, although shortage of sample precluded identification some quaternary carbons. The relative configurations corresponded to those of most of the neoclerodanes, particularly 15 , as demonstrated largely by ${ }^{1} \mathrm{H}$ NMR coupling constants. The structure shown in Fig. 1 was assigned to 17 , fatimanol U. 
Compound 18. The HRESIMS contained ions at $m / z$ 803.3255 [2 $\mathrm{M}+\mathrm{Na}]^{+}$(calc 803.3255) and $\mathrm{m} / z$ $413.1568[\mathrm{M}+\mathrm{Na}]^{+}$(calc 413.1576) confirming the formula $\mathrm{C}_{21} \mathrm{H}_{26} \mathrm{O}_{7}$. An ion was also seen at $\mathrm{m} / z 371$ $[\mathrm{M}+\mathrm{H}]^{+}$. The ${ }^{13} \mathrm{C}$ NMR spectrum (in $\left.\left(\mathrm{CD}_{3}\right)_{2} \mathrm{SO}\right)$ contained discrete signals for twenty-one carbon atoms: 3 - $\mathrm{CH}_{3}, 4 \cdot \mathrm{CH}_{2}, 8 \cdot \mathrm{CH}, 6 \cdot \mathrm{C}_{\mathrm{q}}$. Combined analysis of the NMR data (Table S6, SI) allowed assignment of all the signals and confirmed that the overall structure was similar to a conventional neoclerodane. However, C-6 was quaternary but not a carbonyl (cf. 2). Two methoxy groups were also evident. The upper part of the structure comprised a furan, with the usual chemical shifts (position-13: $\delta_{\mathrm{C}} 125.4$; position-14: $\delta_{H}$ 6.52, $\delta_{C} 109.2$; position-15: $\delta_{H} 7.72, \delta_{C} 145.0$; position- 16 : $\left.\delta_{H} 7.82, \delta_{C} 141.2\right)$. HMBC cross-peaks from C13 linked this to $\mathrm{H}-12$ ( $\delta 5.48)$ and to one $\mathrm{H}-11$ ( $\delta 2.42)$. The other $\mathrm{H}-11$ ( $\delta 2.57)$ was identified by COSY cross-peaks to $\mathrm{H}-12$ and to its geminal partner $\mathrm{H}-11$. HSQC then located $\mathrm{C}-12(\delta 71.6)$ and $\mathrm{C}-11(\delta 40)$. The carbonyl (C-20) of the $y$-lactone resonated at $\delta 176.6$ and showed an HMBC cross-peak to the downfield $\mathrm{H}-11$. It also gave an $\mathrm{HMBC}$ with $\mathrm{H}-10$ ( $\delta 2.45)$ and both $\mathrm{H}-11$ gave $\mathrm{HMBC}$ correlations with $\mathrm{C}-9$ ( $\delta 53.0)$, confirming the attachment of the spiro-lactone. In the lower bicycle, $\mathrm{H}-10$ also correlated in HMBC with C-8 ( $\delta 35.8)$, from which $\mathrm{H}-8$ ( $\delta 2.01)$ and the methyl doublet $\mathrm{H}-17$ ( $\delta 0.92)$ were identified. COSY from $\mathrm{H}-8$ led to one $\mathrm{H}-7$ ( $\delta$ 1.87) and thence to its geminal partner $\mathrm{H}-7$ ( $\delta$ 2.27). HSQC identified C-7 ( $\delta 39.6)$. Two-bond HMBC linked both $\mathrm{H}-7$ to $\mathrm{C}-6$ ( $\delta$ 109.16). This chemical shift implied that $\mathrm{C}-6$ was an acetal or hemiacetal carbon, confirmed by a 3-bond HMBC with the upfield methoxy group MeO- 6 ( $\delta$ 2.97). Both $\mathrm{H}-7$ also showed $\mathrm{HMBC}$ correlations to $\mathrm{C}-5$ ( $\delta$ 137.4), an alkene carbon. Thus $\mathrm{C}-19$ is missing from the usual neoclerodane structure. $\mathrm{H}-10$ is present, thus the other alkene carbon is $\mathrm{C}-4$ ( $\delta 139.5)$. HMBC from C-4 located HO-3 ( $\delta 5.06$ ), from which $\mathrm{H}-3$ was shown (COSY) to be at $\delta 4.06$ and thence $\mathrm{C}-3$ was identified at $\delta 51.5$ by HSQC. COSY joined $\mathrm{H}-3$ to both $\mathrm{H}-2(\delta 1.39, \delta 2.01)$ and HMBC from HO-4 identified $\mathrm{C}-2(\delta 33.0) . \mathrm{CH}_{2}-1$ resonated at $\delta_{H} 1.25, \delta_{H} 2.27$, and $\delta_{C} 23.7$. In the bottom dihydrofuran, HMBC from C-3 and C-5 identified H-18 ( $\delta$ 6.02) and HSQC confirmed C-18 ( $\delta$ 107.0), where the chemical shifts were consistent with an acetal. One arm of this acetal was the oxygen linking through to C- 6 and the other was a methoxy $(\mathrm{MeO}-18)\left(\delta_{\mathrm{H}} 3.15, \delta_{\mathrm{C}} 51.5\right)$, as shown by $\mathrm{HMBC}$ to $\mathrm{H}-18$ and $\mathrm{C}-18$.

Turning to the configuration of 18 , the ${ }^{1} \mathrm{H}$ chemical shift of MeO-6 was unusually low ( $\left.\delta 2.97\right)$. Examination of a molecular model showed that this methyl group, if on the lower face, would be held in the anisotropic shielding zone of the C-20 carbonyl; thus it is likely to be located on the lower face of the fused tricycle. The configuration at the other acetal C-18 could not be determined, although it was clear that only one diastereoisomer was present. $\mathrm{A}^{1} \mathrm{H}$ NMR spectrum of 18 was also obtained in $\mathrm{CDCl}_{3}$, which was consistent with the structure determined above. The novel structure shown in Fig. 1 was assigned to 18, fatimanol V.

Compound 19. Instability under MS conditions precluded obtaining useful mass spectra. The ${ }^{13} \mathrm{C}$ NMR spectrum (in $\left(\mathrm{CD}_{3}\right)_{2} \mathrm{SO}$ ) (Table S7, SI) contained twenty-two discrete ${ }^{13} \mathrm{C}$ signals: $3 \cdot \mathrm{CH}_{3}, 8 \cdot \mathrm{CH}_{2}, 5 \cdot \mathrm{CH}, 6$ - $\mathrm{C}_{\mathrm{q}}$. The combined spectra showed it to be a modified neoclerodane. The upper ring was a furanone, with the $\mathrm{H}-16$ protons resonating accidentally equivalently as a singlet at $\delta 4.86$, with $\mathrm{C}-16$ at $\delta 73.53$. These chemical shifts suggested a y-lactone. Three-bond HMBC cross-peaks from $\mathrm{H}-16$ identified lactone 
carbonyl C-15 ( $\delta$ 173.4) and C-14 ( $\delta$ 114.0), with H-15 ( $\delta$ 5.96) identified by HSQC. A 2-bond HMBC identified C-13 ( $\delta$ 174.4). Initially, it was unexpected that the resonance for C-13 (an alkene) would be downfield of that for C-15 (a carbonyl) but comparison with the chemical shifts ${ }^{29}$ for 4-ethyl-5Hfuran-2one gave precedent. Moreover, the assignment was shown to be correct by HMBC from H-12 ( $\delta 2.25)$ to C13. HSQC then identified the other $\mathrm{H}-12$ ( $\delta 2.15)$ and $\mathrm{C}-12$ ( $\delta$ 21.9). $\mathrm{HMBC}$ from both $\mathrm{H}-12$ led to $\mathrm{C}-11$ ( $\delta$ 34.38), confirmed by interactions of $\mathrm{C}-12$ with both $\mathrm{H}-11(\delta 1.50, \delta 1.98)$. C-9 resonated at $\delta 38.0$ and was linked by HMBC to the two upfield methyl signals, $\delta 0.78$ for $\mathrm{H}-17$ and $\delta 0.65$ for $\mathrm{H}-20$. A 3-bond HMBC

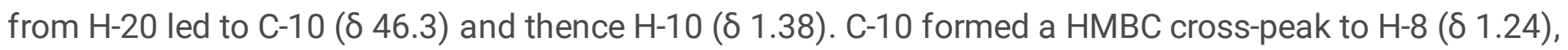
from which $\mathrm{C}-8(\delta$ 4.1) was identified by HSQC. Confirmation was supplied by HMBC from C-8 to C-17 and $\mathrm{C}-20$. A weak 4-bond $\mathrm{HMBC}$ from $\mathrm{H}-17$ to $\mathrm{C}-6(\delta 72.7)$ identified the latter. $\mathrm{H}-6$ resonated at $\delta 3.63$, indicating the $\mathrm{OH}$. $\mathrm{HMBC}$ from $\mathrm{C}-6$ to $\delta_{\mathrm{H}} 1.43$ led to identification of one $\mathrm{H}-7$, from which the other $\mathrm{H}-7$ ( $\delta$ 1.50) and C-7 ( $\delta 34.41)$ were correlated by HSQC. C- 6 also gave an HMBC cross-peak with H-10, closing the lower-right carbocycle, while a cross-peak from the upfield $\mathrm{H}-7$ located $\mathrm{C}-5$ ( $\delta 45.2)$. C-5 was shown to carry $\mathrm{C}-19$ by $\mathrm{HMBC}$ to both $\mathrm{H}-19$ ( $\delta 4.34, \delta 4.49$, geminally coupled doublets). Both $\mathrm{H}-19$ linked on to the carbonyl at $\delta$ 170.8, demonstrating that C-19 carries an AcO- group. C-5 also gave HMBC cross-peaks to both $\mathrm{H}-18(\delta 2.84, \delta 3.09)$. HSQC identified C-18 ( $\delta 43.0)$ and 2-bond HMBC from both $\mathrm{H}-18$ located the signal for $\mathrm{C}-4$ at $\delta$ 69.6. A weaker HMBC interaction between $\mathrm{C}-4$ and $\mathrm{HO}-3$ ( $\delta$ 7.76) linked on to $\mathrm{C}-3$ ( $\delta$ $64.5)$ and thence $\mathrm{H}-3$ ( $\delta 3.82)$. Finally, the remaining methylenes were identified through further HMBC correlations $(\mathrm{H}-2$ : $\delta 1.24, \delta 1.55, \mathrm{C}-2 \delta 34.42 ; \mathrm{H}-1$ : $\delta 1.50, \delta 1.66, \mathrm{C}-1 \delta 20.0)$. The structure shown in Fig. 1 was assigned to 19 , fatimanol $\mathrm{W}$.

Compound 20. Instability under MS conditions precluded obtaining useful mass spectra. The ${ }^{13} \mathrm{C}$ NMR spectrum (in $\left(\mathrm{CD}_{3}\right)_{2} \mathrm{SO}$ ) (Table S7, $\mathrm{SI}$ ) contained twenty discrete ${ }^{13} \mathrm{C}$ signals: $2 \cdot \mathrm{CH}_{3}, 8 \cdot \mathrm{CH}_{2}, 5 \cdot \mathrm{CH}$, and 5 - $\mathrm{C}_{\mathrm{q}}$. The combined NMR spectra showed it to be very similar to 19 , with similar HMBC and HSQC connectivities. Only the points of significant difference are discussed here. This compound lacked an acetate ester. Relative to 19 , the signals for $\mathrm{H}-19$ and $\mathrm{C}-19$ have moved markedly upfield $\left(\delta_{H} 3.78, \delta_{H} 3.98\right.$, $\delta_{\mathrm{C}}$ 60.3). This was consistent with the $\mathrm{C}-19$ substituent being HO-. This was confirmed by observation of the HO-19 signal as a dd at $\delta 4.12$, with $\mathrm{HMBC}$ to $\mathrm{C}-5$ and $\mathrm{C}-19$. Changes in chemical shift were also seen for the oxirane $\mathrm{H}-18(\delta 2.70, \delta 2.89)$ and $\mathrm{C}-18(\delta 40.5)$, and for $\mathrm{C}-5(\delta 46.9)$, reflecting changes in steric effects in that region and the absence of through-space effects from an ester carbonyl. Thus $\mathbf{2 0}$ (fatimanol X) was the desacetyl analogue of 19, with the structure shown in Fig. 1.

The occurrence of orthoesters in plant natural products was reviewed by Liao et al. in 2008. ${ }^{28}$ Orthoacetates have been reported in only a limited number of frameworks, principally the daphnane diterpenoids, phragmalin limonoids, bufadienolide and ergostanoid steroids. Several of these diterpene orthoacetates have potent biological activities, including systemic toxicity. In each case, the three oxygen atoms of the orthoacetate unit were situated appositely in space for formation of the orthoester and the rigidity of the framework of the diterpene contributed to the stability of this usually highly acid-labile functionality. We propose the mechanism shown in Figure 3 for formation of the orthoacetate in 1. Proposed intermediate 23 is 19 -acetylteulepicin, reported by Savona et al. ${ }^{16}$ to be a secondary metabolite 
in T. buxifolium and the formal oxidation product of $\mathbf{2}$ at the lactol. It is therefore feasible that $\mathbf{2} 3$ is the true biosynthetic precursor of 1 in T. yemense. The carbonyl oxygen of the acetate attacks the adjacent electrophilic ketone carbonyl from the lower face, generating intermediate $\mathbf{2 4}$. Here the alkoxide anion is held close to the $\mathrm{CH}_{2}$ of the electrophilic oxirane and attacks it, opening the strained ring and forming a new bond. Finally, the new alkoxide in $\mathbf{3 0}$ is perfectly placed for attack as the electrophilic carbon of the acetate to form the orthoester 1 . Bruno et al. ${ }^{30}$ observed a related cyclisation from chemical pyrolysis of fruticolone (a constituent of $T$. fruticans) at $200^{\circ} \mathrm{C}$ and a chemical acid-catalysed epoxyester-orthoester rearrangement has been reported ${ }^{31}$ in a synthesis of petuniasterone $D$.

Neoclerodanes with the A-ring contracted to a cyclopentane, as in 13 , have been reported previously as plant natural products but with more complex substitution patterns. Examples with a cyclobutene fused to the cyclopentane were reported in the 1980 s. $^{32,33}$ Ring-contracted neoclerodanes were later identified ${ }^{34-}$ 37 from Pteronia, Conyza, and Microglossa species. In these neoclerodanes, there is extensive transannular bridging. Fatimanol Q (13) is the simplest ring-contracted neoclerodane identified to date. Bohlmann's group suggested that their ring-contracted compounds had arisen from rearrangements involving migration of $\mathrm{C}-2$ to bond with $\mathrm{C}-4$. Mechanisms proposed include protonation of a hydroxy group at $\mathrm{C}-4$ to initiate the rearrangement, ${ }^{34}$ trapping the aldehyde formed from $\mathrm{C}-3$ with a hydroxy group at $\mathrm{C}-10^{34,35}$ and formation of a C-1 $=\mathrm{C}-10$ double bond. ${ }^{34,36,37}$ In each case, the $\mathrm{C}-10$ position is oxidised. However, in the present case, $\mathrm{C} 10$ is not oxidised with either an oxygen function or an alkene. We propose the mechanism in Figure 4 for the biosynthetic ring-contraction. In this mechanism, the rearrangement is triggered by protonation and ring-opening of the strained oxirane. The leaving group oxygen is on the lower face of the ring and thus almost antiperiplanar to the $\mathrm{C}-3-\mathrm{C}-2$ bond. The oxirane-opening and the migration of C-2 are probably concerted, given this conformation. C-2 will approach C-4 from the opposite side to the leaving group, resulting in stereochemical inversion at $\mathrm{C}-4$. This places $\mathrm{C}-18$ on the upper face and the newly generated carbocation (C-3) on the lower face, where it can readily form a hemiacetal with HO-19. This hemiacetal closes the second 5-membered ring such that the two 5-membered rings are cisfused, an energetically favoured arrangement.

Acid anhydrides are relatively uncommon in natural products, owing to their potential for electrophilic reactivity and hydrolysis. However, we have firmly identified $\mathbf{1 0}$ as having a succinic anhydride moiety as the upper ring; this is the first such neoclerodane to be reported. Only one natural product containing a simple (non-fused) succinic anhydride, tubogenic anhydride A, has previously been isolated, from Aspergillus tubingensis. ${ }^{38}$

Compounds $2,3,7-9,11,12,14-17,19,20$ contain the conventional neoclerodane carbon framework with various differences in oxidation level, acetylation, bridging rings and ring-opening at the C-4/C-18 oxirane, whereas 4-6,18 lack C-19. The C-12-C-20 lactol in 2 has precedent in gnaphalin (isolated from $T$. gnaphalodes), ${ }^{39}$ although the latter lacks $\mathrm{HO}-3$. The $\mathrm{C}-19-\mathrm{C}-20$ bridging lactone of $3,7,10$ is present in teulepicephin ${ }^{15}$ and many other neoclerodanes. Compound $\mathbf{1 1}$ contains a related bridging acetal, giving a rigid polycyclic structure. This polycycle is also present in teucrin $\mathrm{P}_{1}$ (also from $T$. gnaphalodes), ${ }^{40}$ 
teupyrenone (from T. pyrenaicum), ${ }^{41}$ and teupolin III, ${ }^{42}$ although the latter do not have the additional lower fused tetrahydrofuran to stiffen the structure further. The upper hydroxyfuranone hemiacetal in $\mathbf{7}$ is also present in the neoclerodane salvidivin (from Salvia divinorum) ${ }^{43}$ whereas the methoxyfuranone acetal moiety in $\mathbf{8 , 9}$ has precedent in the labdane 15-methoxyvelutine C (from Marrubium thessalum) ${ }^{44}$ Most neoclerodanes have the $12-S$ configuration, so the identification of 16 as a $12-R$ neoclerodane is noteworthy. Gács-Baitz et al. ${ }^{42}$ used NOE NMR spectroscopy to determine configuration at C-12 in neoclerodanes featuring the upper aromatic furan and the spiro-lactone but did not have an exact epimeric pair for their study; $\mathbf{1 5}$ and $\mathbf{1 6}$ are exact epimers which facilitated their stereochemical identification. The lower hydroxyfuranone hemiacetal of 4,5 and the corresponding methoxyfuranone acetal feature of 6 have scant precedent, in teucvisin $C^{45}$ and cracroson $B,{ }^{46}$ respectively, while the dimethoxydihydrofuran diacetal of $\mathbf{1 8}$ is completely novel in the series. The ajugamarins and related neoclerodanes have the upper furanone unit of 19 and 20 but all known ajugamarins are oxygenated at C- $-12 .{ }^{47}$

Compounds 1-12 were evaluated for their ability to enhance the glucose-triggered secretion of insulin by freshly isolated murine pancreatic islets, using our previous assay. ${ }^{48}$ In negative-control islets, insulin secretion was $9.1 \pm 0.3 \mathrm{ng}$ islet ${ }^{-1} \mathrm{~h}^{-1}$, triggered by glucose $(16.7 \mathrm{mM}$ ) (Fig. 5). This release was increased 2.2-fold by the standard drug tolbutamide $\left(20.2 \pm 1.3 \mathrm{ng}\right.$ islet $\left.^{-1} \mathrm{~h}^{1}\right)$. The tested compounds showed a range of activities. Compounds 1,2,12 showed little or no effect on the secretion of insulin. Compounds 3-6 and 11 increased the glucose-triggered release of insulin by approximately the same extent as the positive control tolbutamide. Encouragingly, 7-10 showed strong enhancement of insulin secretion, by $3-4$, although these are not as potent as the coumarins cluteolin D and clueolin $\mathrm{J}$ (from Clutia lanceolata). ${ }^{49}$

\section{Conclusions}

We report the isolation and identification of twenty new neoclerodanes from the traditional medicinal plant $T$. yemense. Compound 1 contains an orthoacetate, which is previously unreported in naturallyoccurring neoclerodanes. As shown (Fig. 3), the acetate, oxirane and ketone groups in proposed precursor 23 are appositely located to facilitate formation of the orthoester; precursor $\mathbf{2 3}$ is 19 -acetylteulepicin, previously identified in $T$. buxifolium. The upper (tetrahydro)furan unit in 10 is a succinic anhydride, a reactive moiety not often found in plants but presumably stable in the arid climate in which $T$. yemense grows in nature. Compound 13 results from a relatively unusual ring-contracting skeletal rearrangement during biosynthesis. Interestingly, 7-10 were found to enhance the glucose-triggered release of insulin from isolated murine pancreatic islets to a greater extent than the standard anti-diabetic drug tolbutamide; these compounds represent new leads for the development of treatments for this widespread disease.

\section{Experimental Section}


General analytical and chromatographic procedures. See SI.

Plant material. Teucrium yemense (Defl.) was collected in February 2014, from Akabat Al-Abna, Baljurashi, Saudi Arabia. The collected material was identified by taxonomist Dr. M. Yusuf, College of Pharmacy, King Saud University (KSU), Riyadh, Saudi Arabia. A voucher specimen (\# 15292) has been logged at the herbarium of the College of Pharmacy, KSU.

Extraction and isolation. The air-dried and coarsely ground powdered aerial parts of $T$. yemense $(1.6 \mathrm{Kg})$ were first defatted with hexane and then extracted with $\mathrm{MeOH}$. Evaporation of the solvent from the latter gave a sticky dark mass $(388.6 \mathrm{~g})$. This was suspended in water and extracted with EtOAc, then $\mathrm{BuOH}$. Evaporation of the solvent from the $\mathrm{BuOH}$ extract gave a residue $(43.0 \mathrm{~g})$. This residue was subjected to column chromatography (silica gel, mesh size 230-400, hexane $\rightarrow$ EtOAc / hexane (3:1)) to afford fortyfive fractions. Fifteen of these fractions were subjected to radial centrifugal chromatography (Chromatotron $\left.{ }^{\circledR}\right)\left(\mathrm{CH}_{2} \mathrm{Cl}_{2} / \mathrm{MeOH} 19: 1\right)$, followed by reverse-phase HPLC (C18 column) to give new compounds 1-20, along with some known compounds. The detailed isolation scheme is shown in the SI as Figure S208.

Fatimanol F (1). Colourless gum; IR 3536, 2970, 1761, 1642, $1218 \mathrm{~cm}^{-1} ;{ }^{1} \mathrm{H}$ NMR, ${ }^{13} \mathrm{C}$ NMR, COSY, HSQC, HMBC, see Sl; HRESIMS (+ve) $m / z 457\left[\mathrm{M}+\mathrm{K}^{+}, 441.1510[\mathrm{M}+\mathrm{Na}]^{+}, 419.1690[\mathrm{M}+\mathrm{H}]^{+}, 401[\mathrm{M}+\mathrm{H}-\right.$ $\left.\mathrm{H}_{2} \mathrm{O}\right]^{+}$; HRESIMS (-ve) $\mathrm{m} / \mathrm{z} 463.1605[\mathrm{M}+\text { formate }]^{-}, 453.1316\left[\mathrm{M}+{ }^{35} \mathrm{Cl}\right]^{-}$.

Fatimanone B (2). Colourless gum; IR 3478, 2937, 1796, 1712, 1325, $1238 \mathrm{~cm}^{-1}$; ${ }^{1} \mathrm{H}$ NMR, ${ }^{13} \mathrm{C}$ NMR, COSY, HSQC, HMBC, see SI; HRESIMS (+ve) $m / z 421.1855[\mathrm{M}+\mathrm{Na}]^{+}$.

Fatimanol G (3). White amorphous powder; IR 3513, 2401, 1716, 1533, $1202 \mathrm{~cm}^{-1} ;{ }^{1} \mathrm{H} \mathrm{NMR},{ }^{13} \mathrm{C}$ NMR, COSY, NOESY, HSQC, HMBC, see Sl; HRESIMS (+ ve) $m / z 409\left[\mathrm{M}+\mathrm{H}^{+}, 379.1747\left[\mathrm{M}+\mathrm{H}-\mathrm{H}_{2} \mathrm{C}=\mathrm{O}\right]^{+}\right.$; HRESIMS (-ve) $m / z 407.1690\left[\mathrm{M}-\mathrm{H}^{-}\right.$.

Fatimanol H (4). Colourless gum; IR 3616, 3014, 1715, 1701, 1575, $1202 \mathrm{~cm}^{-1} ;{ }^{1} \mathrm{H}$ NMR, ${ }^{13} \mathrm{C}$ NMR, COSY, NOESY, HSQC, HMBC, see Sl; HRESIMS (+ ve) $m / z 361[\mathrm{M}+\mathrm{K}]^{+}, 383.1113[\mathrm{M}+\mathrm{Na}]^{+}, 361[\mathrm{M}+\mathrm{H}]^{+}$.

Fatimanol I (5). Colourless gum; IR 3618, 2034, 1721, 1763, 1715, $1202 \mathrm{~cm}^{-1} ;{ }^{1} \mathrm{H}$ NMR, ${ }^{13} \mathrm{C}$ NMR, COSY, HSQC, HMBC, see Sl; HRESIMS (+ ve) $m / z$ 827.2509 [2 M + Na $]^{+}, 425.1197[\mathrm{M}+\mathrm{Na}]^{+}, 403.1378[\mathrm{M}+\mathrm{H}]^{+}$.

Fatimanol J (6). Colourless gum; IR 3593, 3132, 1731, 1726, 1704, 1303, $1271 \mathrm{~cm}^{-1} ;{ }^{1} \mathrm{H} \mathrm{NMR},{ }^{13} \mathrm{C} \mathrm{NMR}$, COSY, HSQC, HMBC, see SI; HRESIMS (+ ve) $m / z 397.1248[\mathrm{M}+\mathrm{Na}]^{+}, 375.1429$.

Fatimanol K (7). Colourless gum; IR 3433, 2971, 1769, 1737, $1221 \mathrm{~cm}^{-1} ;{ }^{1} \mathrm{H}$ NMR, ${ }^{13} \mathrm{C}$ NMR, COSY, NOESY, HSQC, HMBC, see SI; HRESIMS (-ve) $m / z 425.1459$ [M - H] ${ }^{-}$. 
Fatimanol L (8). White amorphous powder; IR 3615, 3062, 1744, 1734, 1695, 1303, $1188 \mathrm{~cm}^{-1} ;{ }^{1} \mathrm{H}$ NMR, ${ }^{13} \mathrm{C}$ NMR, COSY, NOESY, HSQC, HMBC, see Sl; HRESIMS (+ ve) $\mathrm{m} / z 519.2212[\mathrm{M}+\mathrm{Na}]^{+}$.

Fatimanol M (9). Colourless gum; IR 3546, 2965, 1764, 1752, 1708, $1244 \mathrm{~cm}^{-1} ;{ }^{1} \mathrm{H}$ NMR, ${ }^{13} \mathrm{C}$ NMR, COSY, NOESY, HSQC, HMBC, see Sl; HRESIMS m/z 535.2189 [M+ Na] $]^{+}, 513.2350[\mathrm{M}+\mathrm{H}]^{+}$.

Fatimanol N (10). Colourless gum; IR: 3631, 3114, 1795, 1790, 1689, 1262, $1132 \mathrm{~cm}^{-1} ;{ }^{1} \mathrm{H}$ NMR, ${ }^{13} \mathrm{C} \mathrm{NMR}$, COSY, HSQC, HMBC, see SI; HRESIMS (+ ve) $m / z 427.1596$ [M + H] ; HRESIMS (-ve) $m / z 425.1452$ [M - H] $-$

Fatimanol $\mathrm{O}$ (11). Colourless gum; IR 3414, 3002, 1621, 1417, $1348 \mathrm{~cm}^{-1} ;{ }^{1} \mathrm{H}$ NMR, ${ }^{13} \mathrm{C}$ NMR, COSY, NOESY, HSQC, HMBC, see SI.

Fatimanol P (12). Colourless gum; IR 3584, 3414, 1716, 1419, $1351 \mathrm{~cm}^{-1} ;{ }^{1} \mathrm{H} N M R,{ }^{13} \mathrm{C} \mathrm{NMR}, \mathrm{COSY}$, NOESY, HSQC, HMBC, see SI; HRESIMS m/z 443.1706 [M + Na] $]^{+}, 421.1854[\mathrm{M}+\mathrm{H}]^{+}$.

Fatimanol Q (13). Colourless gum; ${ }^{1} \mathrm{H}$ NMR, ${ }^{13} \mathrm{C}$ NMR, 135DEPT, COSY, HSQC, HMBC, see SI; HRESIMS (+ ve) $m / z 787.3875[2 \mathrm{M}+\mathrm{Na}]^{+}, 729.3844\left[2 \mathrm{M}+\mathrm{Na}-\mathrm{C}_{2} \mathrm{H}_{2} \mathrm{O}_{2}\right]^{+}, 405.1880[\mathrm{M}+\mathrm{Na}]^{+}, 347.1850[\mathrm{M}+\mathrm{Na}-$ $\left.\mathrm{C}_{2} \mathrm{H}_{2} \mathrm{O}_{2}\right]^{+}, 329.1744\left[\mathrm{M}+\mathrm{Na}-\mathrm{C}_{2} \mathrm{H}_{2} \mathrm{O}_{2}-\mathrm{H}_{2} \mathrm{O}\right]^{+}, 311.1639\left[\mathrm{M}+\mathrm{Na}-\mathrm{C}_{2} \mathrm{H}_{2} \mathrm{O}_{2}-2 \times \mathrm{H}_{2} \mathrm{O}\right]^{+} ; \mathrm{HRESIMS}(-\mathrm{ve}) \mathrm{m} / \mathrm{z}$ 427.1970 [M + formate $]^{-}, 417.1689\left[\mathrm{M}+{ }^{35} \mathrm{Cl}\right]^{-}, 381.1920[\mathrm{M}-\mathrm{H}]^{-}$.

Fatimanol R (14). Colourless gum; ${ }^{1} \mathrm{H}$ NMR, ${ }^{13} \mathrm{C}$ NMR, 135DEPT, COSY, HSQC, HMBC, see SI; HRESIMS (+ ve) $m / z 871.4083[2 \mathrm{M}+\mathrm{Na}]^{+}, 447.1985[\mathrm{M}+\mathrm{Na}]^{+}, 425.2167\left[\mathrm{M}+\mathrm{H}^{+}\right.$; HRESIMS (-ve) $m / z 469.2075[\mathrm{M}+$ formate $]^{-}, 459.1795\left[\mathrm{M}+{ }^{35} \mathrm{Cl}\right]$.

Fatimanol S (15). Colourless gum; ${ }^{1} \mathrm{H}$ NMR, ${ }^{13} \mathrm{C}$ NMR, 135DEPT, COSY, NOESY, HSQC, HMBC, see Sl; HRESIMS (+ve) $m / z 779.3248\left[2 \mathrm{M}+\mathrm{Na}^{+}, 401.1567[\mathrm{M}+\mathrm{Na}]^{+}, 379.1748[\mathrm{M}+\mathrm{H}]^{+}, 361.1642[\mathrm{M}+\mathrm{H}-\right.$ $\left.\mathrm{H}_{2} \mathrm{O}\right]^{+}, 343.1537\left[\mathrm{M}+\mathrm{H}-2 \times \mathrm{H}_{2} \mathrm{O}\right]^{+}, 325.1341\left[\mathrm{M}+\mathrm{H}-3 \times \mathrm{H}_{2} \mathrm{O}\right]^{+}$; HRESIMS (-ve) $\mathrm{m} / z 423.1656[\mathrm{M}+$ formate $]^{-}, 377.1605[\mathrm{M}-\mathrm{H}]^{-}$.

Fatimanol T (16). Colourless gum; ${ }^{1} \mathrm{H}$ NMR, ${ }^{13} \mathrm{C}$ NMR, 135DEPT, COSY, NOESY, HSQC, HMBC, see Sl; HRESIMS (+ve) $m / z 779.3250[2 \mathrm{M}+\mathrm{Na}]^{+}, 401.1568[\mathrm{M}+\mathrm{Na}]^{+}, 379.1748[\mathrm{M}+\mathrm{H}]^{+}, 361.1643[\mathrm{M}+\mathrm{H}-$ $\left.\mathrm{H}_{2} \mathrm{O}\right]^{+}, 325.1432\left[\mathrm{M}+\mathrm{H}-3 \times \mathrm{H}_{2} \mathrm{O}\right]^{+}$.

Fatimanol U (17). Colourless gum; ${ }^{1} \mathrm{H}$ NMR, ${ }^{13} \mathrm{C}$ NMR, 135DEPT, COSY, HSQC, HMBC, see Sl; HRESIMS (+ ve) $983.3881[2 \mathrm{M}+\mathrm{Na}]^{+}, 503.1886[\mathrm{M}+\mathrm{Na}]^{+}, 463.1961\left[\mathrm{M}+\mathrm{H}-\mathrm{H}_{2} \mathrm{O}\right]^{+}, 445.1856\left[\mathrm{M}+\mathrm{H}-2 \times \mathrm{H}_{2} \mathrm{O}\right]^{+}$, 403.1750 [M + $\left.\mathrm{H}-\mathrm{H}_{2} \mathrm{O}-\mathrm{AcOH}\right]^{+}, 361.1644\left[\mathrm{M}+\mathrm{H}-2 \times \mathrm{AcOH}^{+}\right.$; HRESIMS (-ve) $\mathrm{m} / \mathrm{z} 525.1974[\mathrm{M}+$ formate $]^{-}, 515.1693\left[\mathrm{M}+{ }^{35} \mathrm{Cl}\right]^{-}, 479.1923[\mathrm{M}-\mathrm{H}]^{-}$. 
Fatimanol V (18). Colourless gum; ${ }^{1} \mathrm{H}$ NMR, ${ }^{13} \mathrm{C}$ NMR, 135DEPT, COSY, HSQC, HMBC, see Sl; HRESIMS (+ ve) $m / z 803.3255[2 \mathrm{M}+\mathrm{Na}]^{+}, 413.1568[\mathrm{M}+\mathrm{Na}]^{+}$.

Fatimanol W (19). Colourless wax; ${ }^{1} \mathrm{H}$ NMR, ${ }^{13} \mathrm{C}$ NMR, 135DEPT, HSQC, HMBC, see SI.

Fatimanol X (20). Colourless gum; ${ }^{1} \mathrm{H}$ NMR, ${ }^{13} \mathrm{C}$ NMR, 135DEPT, HSQC, HMBC, see SI.

\section{Declarations}

\section{Acknowledgements}

The authors acknowledge gratefully the Deanship of Scientific Research at King Saud University for funding through the research group project no. RGP-1438-043. We are thankful for support from the BBSRC Institute Strategic Programme Grant on Energy Grasses and Biorefining (BBS/E/W/10963A01) and from the European Regional Development Fund, through the Welsh European Funding Office for the BEACON project. We also thank Helen C. Phillips (Aberystwyth University) for technical support in mass spectrometry and Muhammad Yousuf (King Saud University) for helpful discussions.

\section{Author contributions}

MN-e-A isolated the compounds, obtained NMR spectra, interpreted spectroscopic data, wrote the first draft of the manuscript; IP obtained and interpreted mass spectra, contributed to overall structural elucidation and writing the manuscript; $\mathrm{BW}$ contributed to analysis of biodata, $\mathrm{SA}, \mathrm{RMH}, \mathrm{AB}$ contributed to the isolation of the compounds; TJW obtained NMR spectra; MDT re-interpreted spectroscopic data to confirm structures, wrote the final manuscript; AJA-R collected the plant and contributed to interpreting spectra, writing the manuscript and the management of the project.

\section{Competing interests}

The authors declare no competing interests.

\section{Additional information}

Supplementary information is available for this paper at \#\#\#.

Correspondence and requests for materials should be addressed to MN-e-A or AJA-R.

\section{References}

1. Moghtader, M. Chemical composition of the essential oil of Teucrium polium L. from Iran. Am.Eurasian J. Agric. Environ. Sci. 5, 843-846 (2009).

2. Ulubelen, A., Topcu, G., Sonmez, U. Chemical and biological evaluation of genus Teucrium. In Bioactive Natural Products (Part D), Studies in Natural Products Chemistry 23; Atta-ur-Rahman, Ed.; 
Elsevier: Amsterdam, pp 591-648 (2000).

3. Chaudhary, S. A. Flora of the Kingdom of Saudi Arabia Illustrated, Ministry of Agriculture and Water, National Agriculture and Water Research Center: Riyadh, Saudi Arabia, Vol. 2, Part 2, p 314 (2001).

4. Bakhtiari, M., Asgarpanah, J. Volatile constituents of Teucrium stocksianum Boiss. fruits from South of Iran. J. Essent. Oil-Bear. Plants 18, 1174-1179 (2015).

5. Tandon, S., Mittal, A. K. Insecticidal and growth inhibitory activity of essential oils of Boenninghausenia albiflora and Teucrium quadrifarium against Spilarctia obliqua. Biochem. Syst. Ecol. 2018, 81, 70-73.

6. Jafarbeigi, F., Samih, M. A., Zarabi, M., Esmaeily, S. The effect of some herbal extracts and pesticides on the biological parameters of Besmisa tabaci (Genn.) (Hem. Aleyrodidae) pertaining to tomato grown under controlled conditions. J. Plant Prot. Res. 52, 375-380 (2012).

7. Pellow, J., Nienhuis, N. Medicinal plants for primary dysmenorrhoea: A systematic review. Compl. Ther. Med., 37, 13-26 (2018).

8. Fatima, N. A review on Teucrium oliveranum, a plant found abundantly in Saudi Arabia. Sci. Int. (Lahore) 28, 1229-1231 (2016).

9. Sattar, E. A., Mossa, J. S., Muhammad, I., El-Feraly, F. S. Neoclerodane diterpenoids from Teucrium yemense. Phytochem. 40, 1737-1741 (1995).

10. Sattar, E. A. Iridoids from Teucrium yemense. Arch. Pharmacal Res. 21, 785-786 (1998).

11. Rahman, M. A., Mossa, J. S., Al-Said, M. S., Al-Yahya, M. A. Medicinal plant diversity in the flora of Saudi Arabia 1: a report on seven plant families. Fitoterapia, 75, 149-161 (2004).

12. Al-Musayeib, N. M., Mothana, R. A., Matheeussen, A., Cos, P., Maes, L. In vitro antiplasmodial, antileishmanial and antitrypanosomal activities of selected medicinal plants used in the traditional Arabian Peninsular region. BMC Complementary Altern. Med. 12, \#49 (2012).

13. Zabihi, N. A. et al. Teucrium polium L. improves blood glucose and lipids and ameliorates oxidative stress in heart and aorta of diabetic rats. Int. J. Prev. Med. 9, \#110 (2018).

14. Khodadadi, S. et al. Teucrium polium improves endothelial dysfunction by regulating eNOS and VCAM-1 genes expression and vasoreactivity in diabetic rat aorta. Biomed. Pharmacother. 103, 1526-1530 (2018).

15. Nur-e-Alam, M. et al. Neoclerodane diterpenoids from Reehal Fatima, Teucrium yemense. J. Nat. Prod. 80, 1900-1908 (2017).

16. Savona, G. et al. Neo-clerodane diterpenoids from Teucrium lepicephalum and Teucrium buxifolium. Phytochem. 25, 2569-2572 (1986).

17. Alcázar, R. et al. Neo-clerodane diterpenoids from three species of Teucrium. Phytochem. 31, 39573966 (1992).

18. Kurimoto, S.-i., Pu, J.-X., Sun, H.-D., Takaishi, Y., Kashiwada, Y. Acylated neo-clerodanes and 19-norneo-clerodanes from the aerial parts of Scutellaria coleifolia (Lamiaceae). Phytochem. 116, 298-304 (2015). 
19. Penchev, P. N., Coll, J., Nicolova, K., Iliev, I. N., Bozov, P. I. Minor diterpenoids from Scutellaria galericulata. Phytochem. Lett. 15, 103-107 (2016).

20. Cheriet, T., Mancini, I., Seghiri, R., Benayache, F., Benayache, S. Chemical constituents and biological activities of the genus Linaria (Scrophulariaceae). Nat. Prod. Res. 29, 1589-1613 (2015).

21. Jiang, Y.-J. et al. neo-Clerodanes from the aerial parts of Salvia leucantha. Tetrahedron 72, 55075514 (2016).

22. Shirota, O., Nagamatsu, K., Sekita, S. Neo-clerodane diterpenes from the hallucinogenic sage Salvia divinorum. J. Nat. Prod. 69, 1782-1786 (2006).

23. Riley, A. P. et al. Synthesis and к-opioid receptor activity of furan-substituted Salvinorin A analogues. J. Med. Chem. 57, 10464-10475 (2014).

24. Roach, J. J., Shenvi, R. A. A review of salvinorin analogs and their kappa-opioid receptor activity. Bioorg. Med. Chem. Lett. 28, 1436-1445 (2018).

25. Al-Yahya, M. A., Muhammad, I., Mirza, H. H., El-Feraly, F. S., McPhail, A. T. Neocleordane diterpenoids and their artifacts from Teucrium olivarianum. J. Nat. Prod. 56, 830-842 (1993).

26. Pascual, C. et al. The $\mathrm{C}-12$ and $\mathrm{C}-20$ configurations of some neo-clerodane diterpenoids isolated from Teucrium species. Phytochem. 25, 715-718 (1986).

27. de la Torre, M. C., Fernandez, P., Rodriguez, B. Thermal rearrangements of some neo-clerodane diterpenoids. Tetrahedron 43, 4679-4684 (1987).

28. Liao, S.-G., Chen, H.-D., Yue, J.-M. Plant orthoesters. Chem. Rev. 109, 1092-1140 (2009).

29. Chen, B.-S., Resch, V., Otten, L. G., Hanefeld, U. Enantioselective Michael addition of water. Chem. Eur. J. 21, 3020-3030 (2015).

30. Bruno, M., Ciriminna, R., Piozzi, F., Rosselli, S., Simmonds, M. S. J. Antifeedant activity of neoclerodane diterpenoids from Teucrium fruticans and derivatives of fruticolone. Phytochem. 52, 1055-1058 (1999).

31. Faraldos, J. A., Giner, J.-L. Biomimetic synthesis of petuniasterone D via the epoxy ester-ortho ester rearrangement. J. Org. Chem. 67, 4659-4666 (2002).

32. Bohlmann, F., Grenz, M., Wegner, P., Jakupóvic, J. Clerodan-Derivate und neuartige Diterpene aus Conyza scabrida DC. Liebigs Ann. Chem., 2008-2020 (1983).

33. Singh, P., Sharma, M. C., Joshi, K. C., Bohlmann, F. Diterpenes derived from clerodanes from Pulicaria angustifolia. Phytochem. 24, 190-192 (1985).

34. Zdero, C., Jakupovic, J., Bohlmann, F. Diterpenes and other constituents from Pteronia species. Phytochem. 29, 1231-1245 (1990).

35. Zdero, C., Ahmed, A. A., Bohlmann, F., Mungai, G. M. Diterpene and sesquiterpene xylosides from East African Conyza species. Phytochem. 29, 3167-3172 (1990).

36. Zdero, C., Bohlmann, F., Mungai, G. M. Rearranged clerodanes and other diterpenes from Microglossa pyrrhopappa. Phytochem. 29, 3233-3241 (1990). 
37. Akimanya, A. et al. Two polymethoxylated flavonoids with antioxidant activities and a rearranged clerodane diterpenoid from the leaf exudates of Microglossa pyrifolia. Phytochem. Lett. 11, 183-187 (2015).

38. Koch, L. et al. Sensitivity of Neurospora crassa to a marine-derived Aspergillus tubingensis anhydride exhibiting antifungal activity that is mediated by the MAS1 protein. Marine Drugs 12, 4713-4731 (2014).

39. Savona, G., Paternostro, M., Piozzi, F. New furanoid diterpenes from Teucrium gnaphalodes L'Her. Tetrahedron Lett. 20, 379-582 (1979).

40. Martiner-Ripoll, M. et al. The absolute stereochemistry of some clerodane diterpenoids frorn Teucrium species. J. Chem. Soc., Perkin Trans. 1, 1186-1190 (1981).

41. García-Alvarez, M. C., Marco, J. L., Rodríguez, B., Savona, G., Piozzi, F. Neo-clerodane diterpenoids from Teucrium pyrenaicum. Phytochem 21, 2559-2562 (1982).

42. Gács-Baitz, E., Papanov, G. Y., Malakov, P. Y., Szilágyi, L. C-12 Stereochemistry of teupolin I and related diterpenoids from Teucrium species. Phytochem. 26, 2110-2112 (1987).

43. Shirota, O., Nagamatsu, K., Sekita, S. Neo-clerodane diterpenes from the hallucinogenic sage Salvia divinorum. J. Nat. Prod., 69, 1782-1786 (2006).

44. Argyropoulou, C.; Karioti, A.; Skaltsa, H. Labdane diterpenes from Marrubium thessalum. Phytochem. 70, 635-640 (2009).

45. Lv, H.-W., Luo, J.-G., Zhu, M.-D., Shan, S.-M., Kong, L.-Y. Teucvisins A-E, five new neo-clerodane diterpenes from Teucrium viscidum. Chem. Pharm. Bull., 62, 472-476 (2014).

46. Qiu, M. et al. New clerodane diterpenoids from Croton crassifolius. Fitoterapia 108, 81-86 (2016).

47. Shimomura, M., Sashida, Y., Ogawa, K. Neo-clerodane diterpenes from Ajuga decumbens. Chem. Pharm. Bull. 37, 996-998 (1989).

48. Nur-e-Alam, M. et al. New flavonoids from the Saudi Arabian plant Retama raetam which stimulate secretion of insulin and inhibit a-glucosidase. Org. Biomol. Chem. 17, 1266-1276 (2019).

49. Ahmed, S. et al. Stimulation of insulin secretion by 5-methylcoumarins, including methylthio- and methylsulfinyl-coumarins, isolated from the Saudi Arabian medicinal plant Clutia lanceolata Forssk. Phytochem. 170, \#112213 (2020).

\section{Figures}




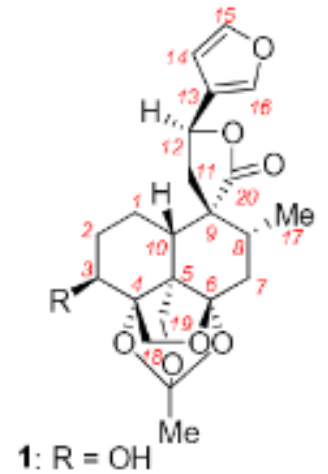

1: $\mathrm{R}=\mathrm{OH}$
13: $\mathrm{R}=\mathrm{H}$

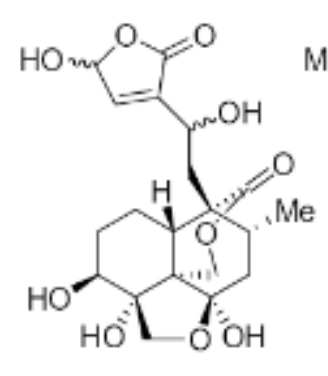

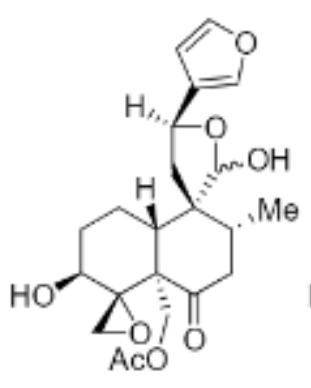

2

3: $\mathrm{R}=\mathrm{Me}$

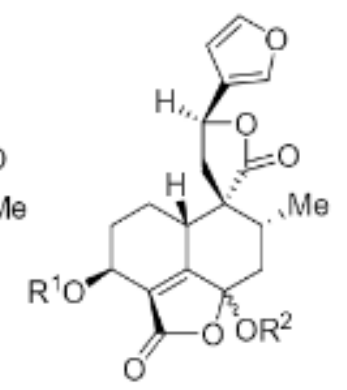

4: $\mathrm{R}^{1}=\mathrm{R}^{2}=\mathrm{H}$

5: $R^{1}=A C ; R^{2}=H$

6: $R^{1}=H_{;} R^{2}=M e$

7

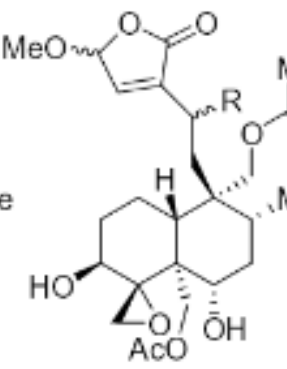

8: $\mathrm{R}=\mathrm{H}$

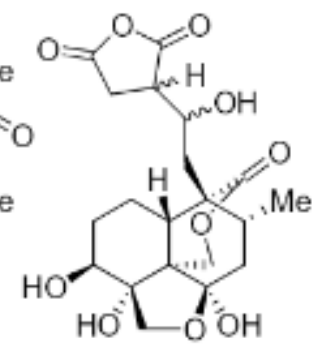

10

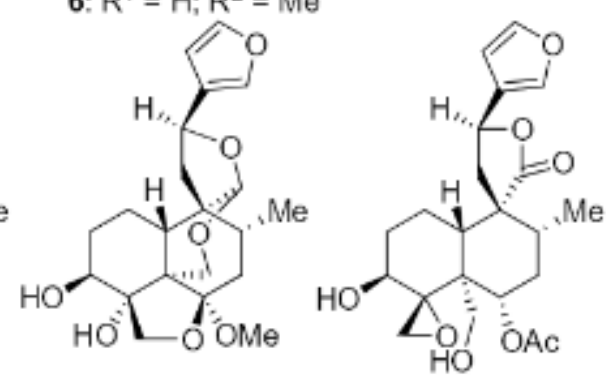

11

12

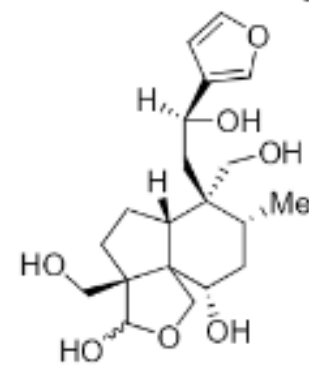

13

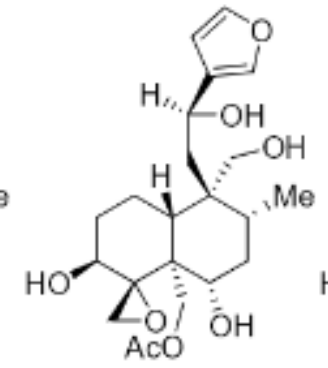

14

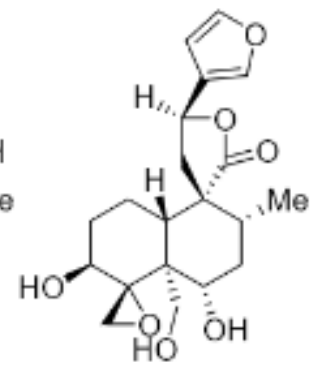

15

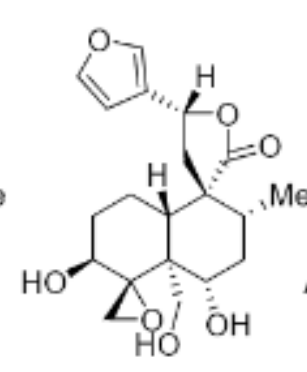

16

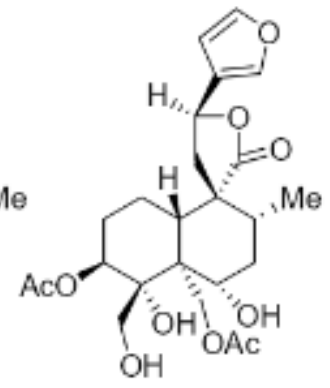

17

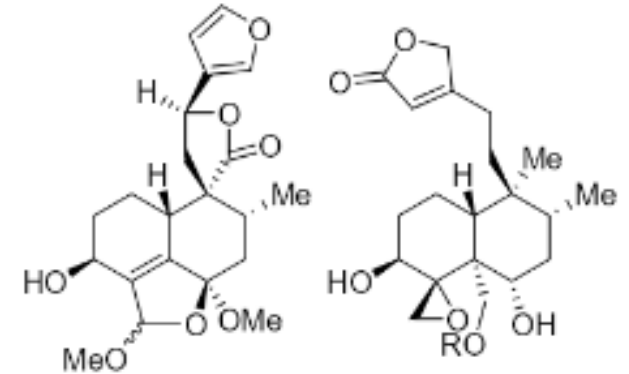

$18 \quad 19 ; \mathrm{R}=\mathrm{AC}$

20: $\mathrm{R}=\mathrm{H}$

Figure 1

Structures of new neoclerodanes isolated from Teucrium yemense (1-20), of the product 21 of pyrolysis of 19-acetylgnaphalin,27 and of previously isolated teulepicephin 22.15 The numbering of the carbon atoms is shown on 1 . 

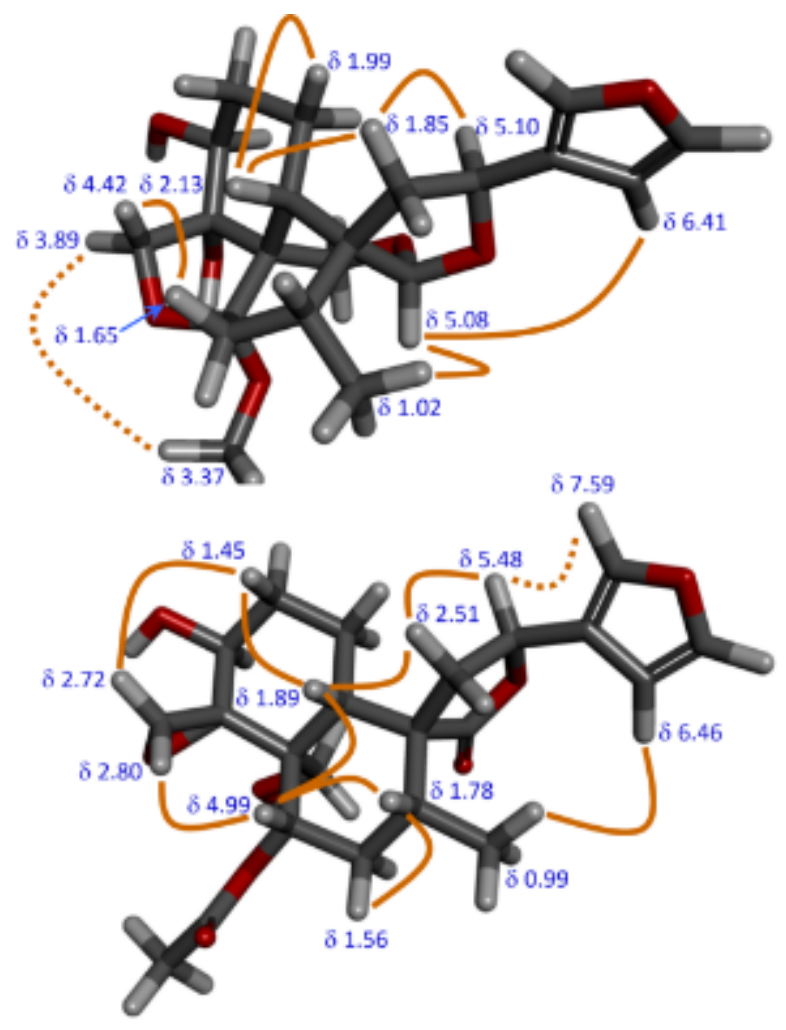

\section{Figure 2}

Upper: Key NOESY interactions confirming the relative stereochemical configurations of the rigid polycycle 11. Lower: Key NOESY interactions confirming the relative stereochemical configurations of 12. A NOESY cross-peak was also observed between H 19 ( $\delta$ 3.90) and H-3. Both conformations were suggested by MM2 minimisation. 

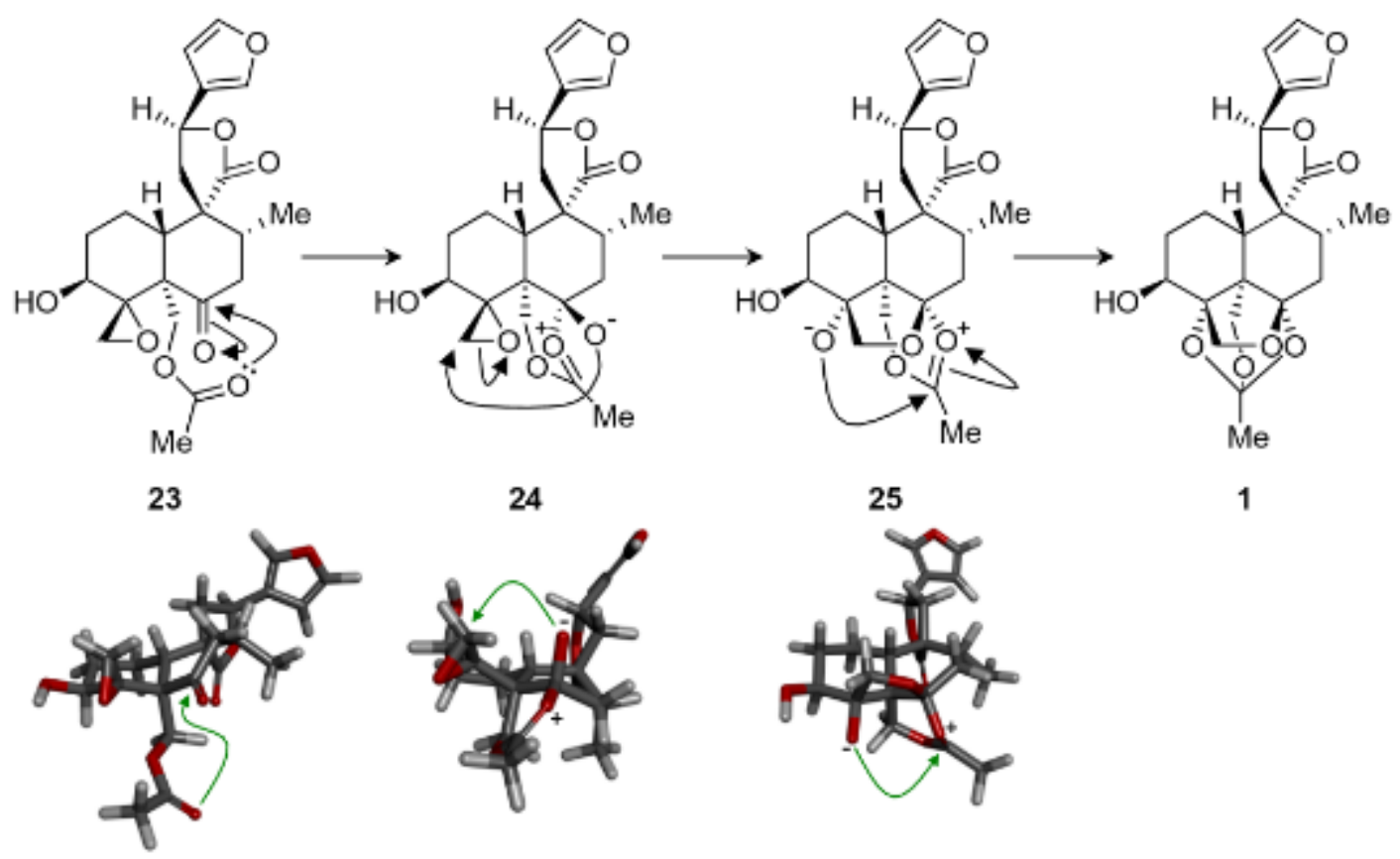

Figure 3

Proposed mechanism of tandem cyclisations forming orthoester 1 from acetate ester 23 , noting apposite positions of ketone and oxirane electrophiles.

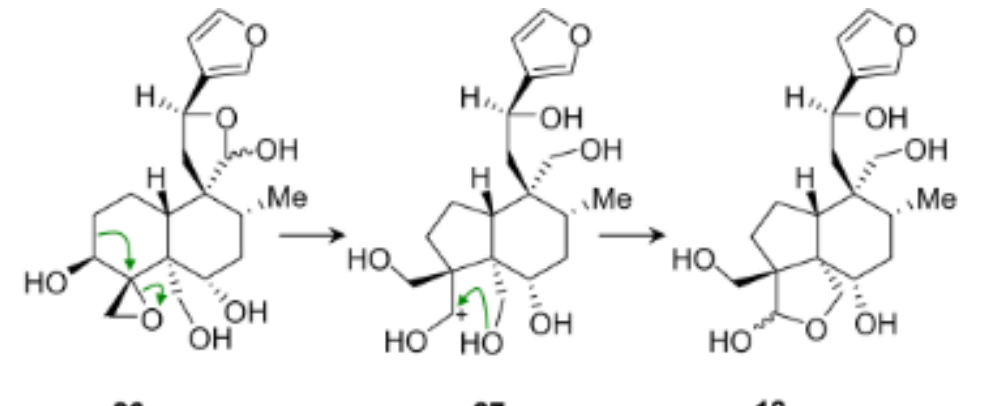

26

27

13

\section{Figure 4}

Proposed mechanism of rearrangement / ring-contraction of 26 to form 13. 


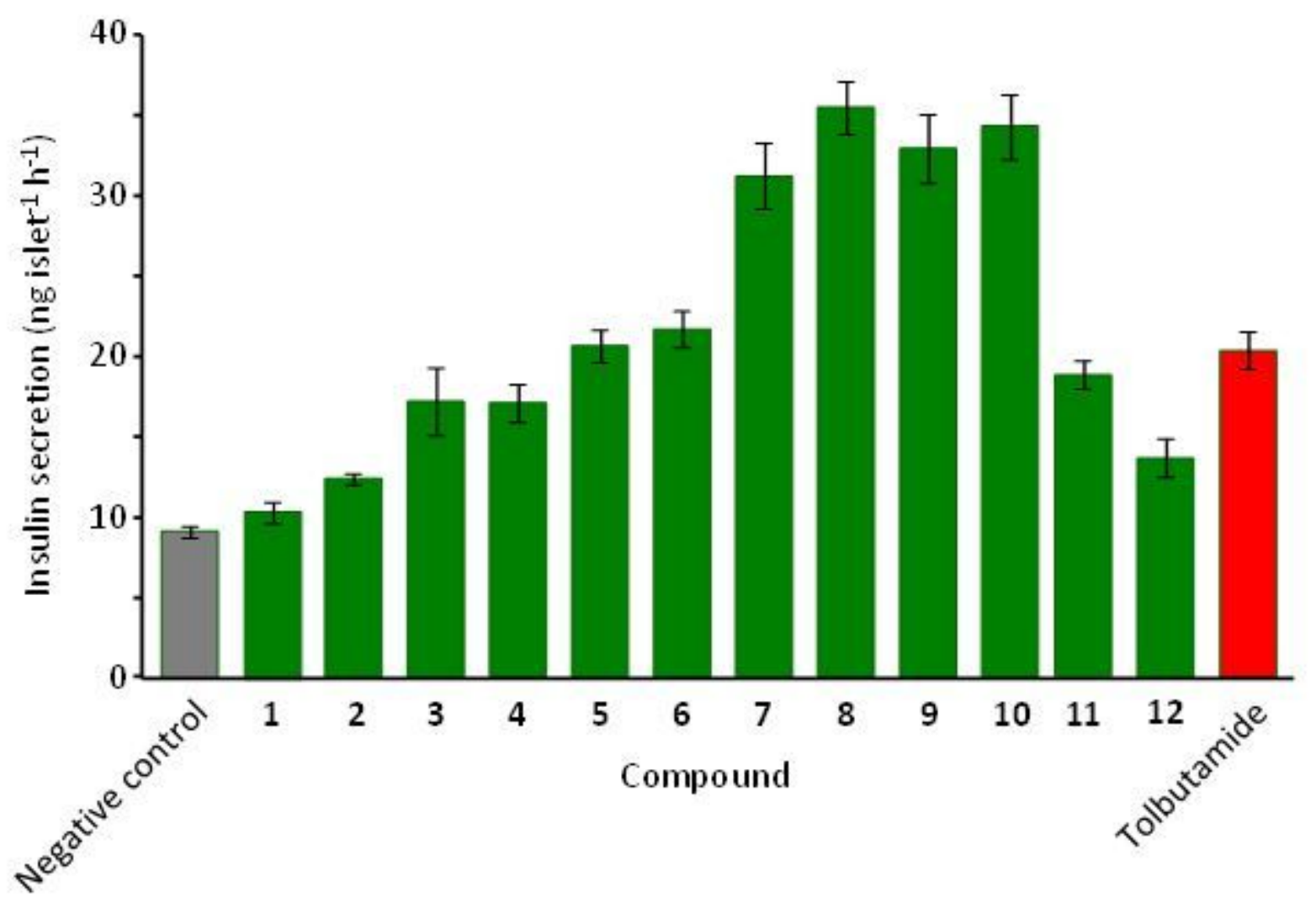

Figure 5

Effects of neoclerodanes 1-12 (from T. yemense) on the glucose-triggered secretion of insulin from murine islets. Islets were incubated for $1 \mathrm{~h}$ at $37^{\circ} \mathrm{C}$ in KRB buffer containing glucose $(16.7 \mathrm{mM})$ in the absence (Negative control) or presence of test compounds and the secreted insulin was measured. Test compounds and positive control tolbutamide were used at the single concentration $200 \mu \mathrm{M}$. Values are mean \pm SD from three independent experiments.

\section{Supplementary Files}

This is a list of supplementary files associated with this preprint. Click to download.

- SISciRepJ116122020.pdf 